\title{
Experimental assessment of the fatigue strength of corroded bridge wires using non- contact mapping techniques
}

Kazuhiro Miyachi, Gifu University

Assistant Professor, Department of Civil Engineering, kmiyachi@gifu-u.ac.jp

Marios Chryssanthopoulos, University of Surrey

Professor, Department of Civil and Environmental Engineering, mkchry@ surrey.ac.uk

Shunichi Nakamura, Tokai University

Professor, Department of Civil Engineering, snakamu@tsc.u-tokai.ac.jp

\section{Abstract:}

This study investigates the fatigue performance of corroded bridge wires by providing characterisation of the corrosion effects through non-contact surface mapping and by undertaking fatigue tests under constant amplitude loading. For the corrosion level investigated, the breakage position in corroded wires was found to be better correlated with maximum area loss rather than pit depth. Using also test results for un-corroded wires, S-N relationships were determined for both that set and the corroded wire set created in this study. The effect of corrosion was quantified through the estimation of the coefficients for both the mean and the design S-N curves.

Keywords: bridge cable; corroded wire; fatigue strength; 3D laser scanner; S-N curves

To appear in: Corrosion Science 


\section{Introduction}

The performance of steel wires in cables and hangers is an important consideration in the life-cycle management of long-span bridges. Early experience from field surveys [1-3] unveiled that, due to the presence of trapped water, highly humid conditions can develop inside the cables leading to wire corrosion, even within relatively short periods compared to the service life of the bridge. Detailed internal inspections of the main cables of two major UK suspension bridges undertaken approximately forty years after opening, namely the Forth Road bridge [4] and the Severn bridge [5], revealed significant wire corrosion at a number of locations. The level of corrosion varied depending on the spatial position of the wires along the length but also within the cross section. With respect to the length, corrosion was worse at lower vertical locations, such as at mid-span [5] whereas with regard to crosssectional variation bottom and side wires appeared to be more affected than their upper and centre counterparts [6]. In these inspections, a number of corroded wires were also found to be broken and several studies have attempted to clarify the mechanism that causes wire breakage, with hydrogen embrittlement and corrosion fatigue being conjectured $[7,8]$.

Notwithstanding the actual cause of breaking, wires in cables and stays of suspension and cable-stayed bridges experience high number of stress fluctuations and are susceptible to fatigue failure. Thus, in recent year research on the fatigue performance of corroded wires has gathered pace, in order to quantify the effect of different levels of corrosion on $S-N$ (Relationships between Stress range and Number of cycles) relationships [9,10]. There is general agreement that the fatigue life of corroded wires is drastically lower than that for un-corroded wires, with the presence of corrosion pits providing fatigue initiation zones and accelerating fatigue crack propagation, culminating in brittle fracture once a critical crack depth has formed. Thus, attention has also been paid to the characterisation of the corrosion surface using non-contact measurements such as 3D laser scanner and image processing $[11,12,13]$. The results have been used in developing prediction methodologies for the remaining life of corroded wires based on fracture mechanics [12] and cellular automata [14]. In another investigation, Lan et al. [15], performed accelerated corrosion tests and developed multi-parameter Weibull model for corrosion-stresslife of individual wires, which was then used to predict the fatigue life of parallel-wire stay cable as a function of the degree of corrosion at different stress range values.

The objective of this paper is to add to the body of work that investigates the fatigue performance of corroded wires by presenting experimental results and developing $S-N$ relationships for corroded wires, whilst also providing detailed characterisation of the corrosion effects through non-contact mapping of the corroded surface. 
The paper is organised as follows: Section 2 presents the experimental methods employed to create and characterise corroded wires in a laboratory environment, followed by a description of the fatigue tests undertaken. The corroded surfaces were analysed using spatial indicators in terms of sectional area loss and corrosion depth in order to explore correlation with fracture locations observed in the fatigue tests. Section 3 contains key results pertaining to corrosion characterisation, the previously mentioned correlation with fracture locations, the development of $S$ - $N$ curves (both mean and design) according to the guidelines issued by the International Institute of Welding and the fatigue strength due to corrosion based on un-corroded and corroded $S$ - $N$ curves. Section 4 summarises the main findings of the present work.

\section{Experimental testing}

\subsection{Specimens}

The 300mm long specimens, shown in Fig.1, are high-strength galvanized steel wires with an average diameter of $5.15 \mathrm{~mm}$ (standard deviation of $0.026 \mathrm{~mm})$ and a nominal tensile strength of $1570 \mathrm{MPa}(0.2 \%$ proof stress of around $1200 \mathrm{MPa}$ ). The amount of the zinc is $331 \mathrm{~g} / \mathrm{m}^{2}$ resulting in a coating thickness of about $50 \mu \mathrm{m}$. The chemical composition of the specimens is given in Table.1 and compared with previously reported values [16,17]. This type of high-strength wires is mainly used for stay-cables and main cables of medium to long span bridges such as cable-stayed bridges and suspension bridges. The wires are produced from thicker steel rods with a higher carbon content (circa $0.8 \%$ ) than structural steel by a process of cold drawing, thus resulting in a wire with high tensile strength but relatively low ductility (about 4\%) [18,19].

\subsection{Accelerated corrosion test}

Inspections of actual stay and suspension wires in bridges have revealed that deterioration starts with the depletion of the zinc coating, followed by mechanisms that involve surface corrosion and the formation of localised pits and transverse cracks. On the basis of field observations, wire corrosion has been categorised visually in four stages, as per the NCHRP guidelines [20]:

Stage 1 - spots of zinc oxidation on the wires;

Stage 2-zinc oxidation on the entire wire surface;

Stage 3-spots of brown rust covering up to $30 \%$ of the surface of a $75-150 \mathrm{~mm}$ length of wire; and 
Stage 4-brown rust covering more than $30 \%$ of the surface of a $75-150 \mathrm{~mm}$ length of wire.

In this work, the wet gauge accelerated corrosion method was adopted, following earlier studies $[3,10,21]$ which showed that it produces a corrosion phenomenon with similar appearance to that observed in actual cables. In accordance with the categorisation proposed by Nakamura and Suzumura $[8,10]$, four corrosion levels can be distinguished:

Initial Stage — nearly initial condition of galvanized steel wire with almost no corrosion;

Level 1 - wire covered by zinc-specific white rust and dots in places with iron-specific red rust;

Level 2 - wire covered by white rust and locally red rust spread; and

Level 3-corrosion in wire further progressed and red rust generation area increased.

As can be seen in Table.2, which compares visually the two categorisation schemes and includes pictures of the specimens produced in this study, the development of the corrosion phenomenon appears to be quite similar. The accelerated corrosion process adopted in this study, which attempts to simulate the real environment following the recommendations given in $[3,22]$, results in a degree of corrosion variation in the specimens at any given exposure time (Table.3). This occurs also in the real environment, with some wires (or their portions) being uniformly corroded and others being much more locally corroded (Table.4) [23, 24]. An alternative approach would have been to follow the accelerated corrosion process based on salt spray suggested in [25], however evidence suggests that in this case there is propensity towards general corrosion with the resulting specimens having a distinctly different appearance [12] compared to the typical specimens shown in Table.2.

Thus, the accelerated corrosion test in this study was conducted as follows. The central $100 \mathrm{~mm}$ of the $300 \mathrm{~mm}$ specimen was designated as the part exposed to corrosion with the two end parts (each of 100mm length) protected by using anticorrosion tape. The end parts were prevented from corrosion since they are placed within the fatigue machine's grips. The specimens were then wrapped with gauze and sprayed with a salt concentration of $0.01 \%$ sodium chloride aqueous solution, on the basis that the salinity of water retained inside the actual suspension bridge cable is of that order $[3,21]$. Next, in order to prevent evaporation of moisture, the specimens were placed in a sealed plastic box (Fig.2a), thus maintaining them in a wet environment. Finally, since a high-temperature environment promotes faster corrosion, the sealed specimens were placed in a thermostatic chamber (Fig.2b, manufactured by ESPEC Co., Japan) and kept at $40^{\circ} \mathrm{C}$ for 150 days (3600 hours). A general purpose abrasive (Scotch-Brite) was used to remove the corrosion products, taking care not to damage the galvanized layer or the base metal. Close visual checks were carried out to ensure that there is no difference in the degree of removal between specimens. The development of corrosion, after removing corrosion products is shown in Fig.3. Visually, 
the corrosion appears similar to the sequence shown in the NCHRP guidelines [20] with coating deterioration and progressive removal followed by the development of localised corrosion sites, some with deeper pits being visible. After 150days exposure, the corroded wires are of a similar appearance to those in Stage 3 of NCHRP Guidelines [20] or Corrosion Level 2, as defined by Nakamura and Suzumura $[8,10]$.

\subsection{Measurement of surface corrosion}

Although existing guidelines offer a visual classification of the corrosion in bridge cables, there is also a need to produce quantitative characterisation measures which can be linked in the future with improved assessment procedures regarding both static and fatigue performance of bridge stays and cables. In this study, a non-contact 3D scanner HD manufactured by Next Engine Inc. (California, USA) was used to measure the surface roughness of corroded wires. The scanning process is based on the principle of a triangulated survey. The laser light is irradiated after striking the object's surface, and the distance between the scanner and the object is calculated by receiving the reflected light. Talcum powder is lightly deposited on the corroded wire's surface to minimize the light reflection of the metal and improve the measurement's accuracy. The scanner has an accuracy of $\pm 0.127 \mathrm{~mm}$, though this depends on the distance to the object and the density of the point cloud created. Therefore, it is important to determine the optimum distance to the object and density of the point cloud before undertaking detailed measurements. The object in question (i.e. the wire specimen) was placed at $165 \mathrm{~mm}$, the shortest possible scanner distance, and the point cloud density was set at 62 points $/ \mathrm{mm}^{2}$, the maximum available for this device, to enable changes in the roughness of corroded wires to be measured with the highest possible accuracy. The actual arrangement consisted of the specimen vertically fixed to an automatic rotary table as shown in Fig.4. The specimen was measured at a particular position and then rotated by 60 degrees. This process was repeated six times to generate the point cloud data of the whole cylindrical surface. As a result, the surface roughness of the three-dimensional corroded wire geometry was successfully obtained by combining the data sets of the six measured perspectives [26]. The scanned data was then analysed in order to obtain quantitative information on the depth, shape and distribution of corrosion. A representative scan and the associated point cloud of a corroded wire are shown in Fig.5. The scanned surface roughness was recorded as point cloud data in a Cartesian coordinate system. After repairing defective parts and eliminating unnecessary duplication using Scan Studio HD [27] the scan data were imported into the QA-Scan software. Here, the corroded wire data were aligned with the CAD generated data of a pristine wire (perfect cylinder) in order to compare and measure their deviations. The pristine wire geometry was created as a perfect cylinder with a diameter of $5.15 \mathrm{~mm}$ on the basis of measurements made 
on the un-corroded parts of the tested wires. It was neither possible (due to high shininess of the pristine surface) nor necessary (due to high repeatability of the diameter measurements) to scan the un-corroded parts of the wires, with the surface data obtained from the CAD model used a reference surface. In order to analyse a large number of collected data in an effective way, the dataset of the corroded part of the specimen which was $100 \mathrm{~mm}$ long was divided into 101 sections with $1 \mathrm{~mm}$ pitch in the longitudinal direction. In order to select an appropriate pitch interval, a range of different values were assessed, namely $0.5 \mathrm{~mm}, 1 \mathrm{~mm}, 2 \mathrm{~mm}, 5 \mathrm{~mm}$ and $10 \mathrm{~mm}$. On that basis, a $1 \mathrm{~mm}$ interval was selected as the results converged to a reasonable accuracy when compared with their counterparts at intervals on either side (i.e. $0.5 \mathrm{~mm}$ and $2 \mathrm{~mm}$ ). In this way the three-dimensional dataset was also visualised in cross-sectional form as shown in Fig.6. A corrosion pit is represented as an inward reduction in the cross-section of the un-corroded wire whereas a local increase indicates the deposit of corrosion product (i.e. rust that could not be removed). It was observed that when corrosion occurs only to some small degree, rust swells, and although the rust surface layer can generally be removed quite readily, there are few instances where dense rust remains at the rust-base steel interface. In such cases, a small local increase in diameter compared to the pristine wire's value might be recorded but this should be ignored as it does not represent real addition of material. In order to verify the measured values using the scanner, additional measurements were conducted using a micrometre (Fig.7a). These were compared with equivalent measurements on the scanned images using a virtual calliper available in the QA-Scan software. The diameter of the corroded test specimen was measured three times at $5 \mathrm{~mm}$ intervals along the corroded part of $100 \mathrm{~mm}$ (in total $21 * 3=63$ measurements), and compared with the corresponding scanned data using the virtual calliper. As can be seen from Fig.7b, comparisons between measurements show that an accuracy with an absolute error of $0.018 \mathrm{~mm}$ (standard deviation $0.019 \mathrm{~mm}$ ) can be achieved. [26, 27]

A final issue related to the processing of the measurements was that the wire specimens exhibited some curvature. This is presumed to be because galvanized steel wire is generally wound around a reel during production and storage. The radius of curvature was estimated by measuring the arc length at mid-length of three specimens. Thus, a radius of curvature of about 5,600 mm was obtained (Fig.8). Since the radius of curvature of galvanized steel wire manufactured in Japan is of the order of 4,000 $\mathrm{mm}$ or more [28], it was concluded that the specimens used in this study had the same general characteristics of galvanized steel wires manufactured in Japan.

In order to match the un-corroded wire geometry with the scanned corrosion surface and determine the axis of 'best-fit' circle, use was made to the equations (1) and (2) proposed by Umbach et al. [29]. The concept enables a standard baseline to be established for measuring deviations from a perfect cylindrical geometry and is, therefore, 
useful in comparative studies and in statistical analyses. It relies on an error function that minimizes the deviations of the corroded specimen from the 'best-fit' un-corroded specimen using the following equations:

$\operatorname{SSE}\left(a_{j}, b_{j}\right)=\min \sum_{i=1}^{m}\left\{\sqrt{\left(X_{i j}-a_{j}\right)^{2}+\left(Y_{i j}-b_{j}\right)^{2}}-r_{j, a v e}\right\}^{2}, j=1,2, \ldots n$

with the average radius $r_{j}$ of the 'best-fit' circle given by

$r_{j, a v e}=\frac{1}{m} \sum_{i=1}^{m} \sqrt{\left(X_{i j}-a_{j}\right)^{2}+\left(Y_{i j}-b_{j}\right)^{2}}, j=1,2, \ldots n$

where the sum of squared errors of prediction SSE $\left(a_{j}, b_{j}\right)$ is dependent on $a_{j}$ and $b_{j}$. In equation (2), $X_{i j}$ and $Y_{i j}$ are the scanned coordinates of the corroded surface pertaining to an initial reference axis. The index $i$ denotes circumferential variation $(i=1,2, \ldots m)$ whereas the index $j$ indicates variation along the length $(j=1,2, \ldots n)$. Finally, $a_{j}$ and $b_{j}$ indicate the correction values that define the centres to the 'best-fit' circles, $a_{j}$ indicates the coordinate of the correction value in the $X$-axis direction, and $b_{j}$ indicates the co-ordinate of the correction value in the $Y$-axis direction. Their range was set between $-0.3 \mathrm{~mm}$ and $0.3 \mathrm{~mm}$, and the analysis was performed at $0.01 \mathrm{~mm}$ pitch intervals. This range is chosen on the basis of an estimated curvature of the specimen over the central length of $100 \mathrm{~mm}$ (With reference to Fig. 8, for a scanned length in the $100 \mathrm{~mm}$ range and a radius of curvature $R=5600 \mathrm{~mm}, H=0.22 \mathrm{~mm}$ is obtained). The values of $\left(a_{j}, b_{j}\right)$ are iterated in such a way that they minimize the function $\operatorname{SSE}\left(a_{j}, b_{j}\right)$.

Once the perfect circle co-ordinates are established, the deviations can be calculated using the corroded specimen data. For example, Fig.9 shows a typical case before and after the use of 'best-fit' analysis. From the best-fit analysis, the minimum value of $\operatorname{SSE}\left(a_{j}, b_{j}\right)$ was found to be equal to 6.01 when the coordinate set $\left(a_{j}=0.15, b_{j}=\right.$ - 0.05) was introduced.

\subsection{Corrosion indicators}

Specimen corrosion characteristics were derived using the method described in the section above. Previous studies $[10,12,15]$ have suggested that it is important to quantify both general corrosion levels and local corrosion patterns, particularly corrosion pits. In this study, indicators for general corrosion (both at sectional and overall scale), as well as for pitting corrosion were investigated. Fig.10a and 10b show the approach taken for estimating corrosion indicators. 
With regard to Fig.10a, a sectional area loss indicator $A_{j}$ was estimated at a pitch of $1 \mathrm{~mm}$ along the corroded length, as per equation (3) below. The critical section (i.e. with maximum area loss) along the corroded length was then defined through equation (4), whereas a general corrosion indicator was defined through equation (5).

$A_{j}=\left(\frac{\pi r_{0}^{2}}{\pi r_{j, \text { ave }}^{2}}-1\right) \times 100$

$A_{\max }=\max \left[A_{j}\right]$ for all $j, j=1,2, \ldots n$

$A_{\text {ave }}=\frac{1}{n} \sum_{j=1}^{n} A_{j}$

where $A_{j}$ is the area loss at any cross-section along the corroded length $(j=1,2, \ldots n), A_{\max }$ is the maximum sectional area loss over the entire corroded length, and $A_{\text {ave }}$ is the average area loss for any given specimen. $r_{0}$ is the average radius of the un-corroded wire and $r_{j, \text { ave }}$ is the average radius from the readings around the circumference $(i=1,2, \ldots m)$ using the co-ordinates of the best-fit circle at any particular cross-section along the corroded length.

With regard to pitting indicators (Fig.10b), a similar approach was followed, namely considering pits at any point along the length, but also defining maximum and average pit sizes in any corroded specimen, as shown by equations (6) to (8).

$d_{j, \max }=\max \left[d_{i j}\right]$ for all $i, i=1,2, \ldots m$

$d_{\max }=\max \left[d_{j, \max }\right]$ for all $j, j=1,2, \ldots n$

$d_{\text {ave }}=\frac{1}{n} \sum_{j=1}^{n} d_{j, \max }$

where $d_{j, \max }$ is the maximum pit depth at any particular section $(j=1,2, \ldots n), d_{\max }$ is the maximum pit depth over the entire corroded length (i.e. the maximum pit depth of any given specimen) and $d_{a v e}$ is an average pit depth.

In conclusion, for both general corrosion and pitting indicators the objective was to have full characterisation at section level, through Equations (3) and (6); followed by a characterisation of the extreme value, through Equations (4) and (7); and, finally, an overall average value, through Equations (5) and (8). Both the extreme and the overall average values are dependent on the investigated length of $100 \mathrm{~mm}$ per specimen, which is considered to be an appropriate scale over which the corrosion phenomenon can be characterised. The definition of section area loss and pit depth indicators was made in the expectation that this would be helpful in characterising the type of failure in the ensuing fatigue tests. 


\subsection{Fatigue test method}

After scanning fatigue tests were conducted on the corroded wire specimens. A $60 \mathrm{~mm}$ length at either end was bonded using epoxy adhesive (3M Scotch-Weld DP190) to an aluminium pipe segment, with a diameter of 10mm and thickness of $2 \mathrm{~mm}$ as shown in Fig.11. This gripping arrangement was adopted in order to avoid end failure during the fatigue test due to the stress concentration that occurs at those points. Thus, the clear specimen length was $180 \mathrm{~mm}$, comprised of a central $100 \mathrm{~mm}$ corroded part and two un-corroded parts, each of $40 \mathrm{~mm}$ length. A servo-hydraulic fatigue testing machine (Instron Co. 1341A, 10t capacity frame; can be used to full capacity for tensile/compression testing, or up to $50 \%$ capacity in fatigue) was used to apply the cyclic load at a frequency of $15 \mathrm{~Hz}$ by pulsating tensile load, as shown in Fig.12. The appropriate fatigue loading was determined by considering two different approaches. The first is based on design considerations for long-span suspension bridges. Table.5 presents the design working stresses in selected suspension bridges built from the 1960's onwards, all using galvanised high-strength steel wires, similar to those tested in this study. Typically, the overall safety factor is in the range of 2 to 2.5 , depending on country and year of construction [30]. Depending on main span length, the live to dead load ratio for such bridges varies from about 8\% (Akashi-Kaikyo, 1991m), to $12 \%$ (Forth road, 1006m), further increasing to circa $16 \%$ for shorter spans (Innoshima, $770 \mathrm{~m}$ ). Overall, this means that a minimum load (representing the dead load component) in the range between 400-600 MPa is a reasonable estimate covering the spectrum of possible values. A cyclic stress range of approximately $200 \mathrm{MPa}$ applied in addition to the minimum value would represent live load variations and is in line with the overall safety factor typically used. On the other hand, the cables in cable-stayed bridges experience higher live to dead load ratios, typically of the order of $30 \sim 40 \%[31,32,33,34]$. In this case, the dead load component would reduce by about $30 \%$ and the cyclic stress range could more than double, compared to the values given earlier. The second approach for determining an appropriate loading regime entailed reviewing literature on fatigue strength of high strength steel wires, both in pristine and corroded condition. Table.6 summarises the findings, and as can be seen there are two options, i.e. fixing $\sigma_{\min }$ or fixing $R$. The latter provides higher consistency if results are used in order to generate $S$ - $N$ curves, whereas the former is more pragmatic if results for specific bridges are required. Bearing in mind all the above, the specific values adopted in this study are presented in Table.6. 
Test results for eighteen corroded wire specimens, all subjected to accelerated corrosion for 150 days, are shown in Table.5. Specimens that failed outside the corroded part or inside the end grips (8 tests) and run-out tests (> $2 * 10^{6}$ cycles, 4 tests) are also included from a corrosion characterisation perspective. From the Table.5, the corrosion level of the wires manufactured in this study with the accelerated corrosion method (the period of 150days) can be seen to be $2.7 \pm 1.1[\%](=1.6 \sim 3.8 \%)$ for $A_{\text {ave }}$ and $0.253 \pm 0.066[\mathrm{~mm}](=0.187 \sim 0.319 \mathrm{~mm})$ for $d_{\text {max }}$.

\subsection{Corrosion surface measurement results}

Contours of the developed cylindrical surface for two representative specimens (nos. 7 and 8) are shown in Fig.13. The horizontal axis represents the corroded length (0 to 100mm) whereas the vertical axis represents the circumferential angle $\left(0^{\circ}\right.$ to $\left.360^{\circ}\right)$. As can be seen, specimen no. 7 is characterised by general corrosion which varies approximately between $0-0.2 \mathrm{~mm}$ over the entire surface area, on the other hand specimen no. 8 shows regions where the corrosion depth has increased locally to about $0.4 \mathrm{~mm}$. These observations are confirmed by considering Figs.14 and 15, showing longitudinal profiles of sectional area loss, $A_{j}$, and maximum sectional pit depth, $d_{j, \max }$, defined by equations (3) and (6) respectively. As might be expected, specimen no. 8 has higher sectional area loss values and a higher average area loss (Fig.14), and the same holds when comparing local corrosion characteristics (Fig.13). Interestingly, as can be evidenced from Table.5, specimen no.8 failed at a section exhibiting high area loss (at $71 \mathrm{~mm}$ ) and not at the section containing the deepest sectional pit (at $46 \mathrm{~mm})$. On the other hand, for specimen no. 4, the critical location in terms of maximum area loss and maximum sectional pit is the same (at $89 \mathrm{~mm}$ ) and this coincided with the fatigue failure location. These observations may help in developing a modelling methodology on how the fatigue performance of corroded wires with known corrosion characteristics (in terms of sectional area loss and pit depth) could be assessed. It is conjectured that both a stress related approach and a fracture mechanics approach could both be relevant. This interplay between critical sections in a corroded wire is explored further in the next section where fatigue failure locations are correlated to both maximum area loss and maximum pit depth.

Figs.16 and 17 provide further information on the corrosion characteristics of the specimens presented in Table.5, by comparing the histograms of average and extreme quantities with respect to area and pit depth. As is often the case, the extreme parameters $\left(A_{\max }, d_{\max }\right)$ show higher variability than the corresponding average values $\left(A_{\text {ave }}, d_{\text {ave }}\right)$, 
which underlines the high scatter observed in fatigue tests. Finally, the relationship between $A_{\text {ave }}$ and $d_{\max }$ is shown in Fig.18, which confirms observations made in previous studies, e.g. [12], namely that average corrosion and pit depth are positively correlated; in fact, for the thirty specimens in Table.5, the correlation coefficient $\rho\left(A_{\text {ave }}, d_{\max }\right)$ $=0.59$.

\subsection{Fatigue test results}

Representative corroded wires after failing in fatigue tests are shown in Fig.19. As can be seen, the specimens have failed inside the corroded part but at different points along the length. Typical fracture surfaces were photographed by SEM (JEOL JSM-7100F) and the whole photograph is shown in Fig.20a. The fracture surface obtained in this study was compared with the fracture surface reported in previous studies [8, 12], and the same tendency was observed with regard to brittle and ductile surfaces. Specifically, corrosion pits were found at the upper part of the brittle fracture surface, and it was confirmed that the feather marks characteristic of brittle fracture surfaces spread in a fan shape from the crack initiation point of the top (Figs.20b and 20c). It can also be seen that the cracks gradually propagated from that starting point until fracture occurred. Dimples characteristic of ductile fracture surfaces can be seen on the ductile surface (Fig.20d).

The relationships between the actual breakage position $L_{F}$ and two possible critical sections, namely the position corresponding to maximum section area loss $L_{A}$, and the position at which the maximum pit depth occurs $L_{d}$ are shown in Figs.21a and 21b. The correlation coefficient $\rho\left(L_{F}, L_{A}\right)=0.51$, whereas the correlation coefficient $\rho\left(L_{F}\right.$, $\left.L_{d}\right)=-0.06$. The same effect can be quantified by comparing the number of specimens that fail at the position of maximum section loss, i.e. $L_{F}=L_{A}$ as opposed to $L_{F}=L_{d}$. In the former it is 11 out of 18 whereas in the latter it is only 6 out of 18 . Therefore, for the level of corrosion present in these specimens, the weakest position within the corroded length is more likely to be at the position of maximum area loss than at the position of maximum pit depth. However, this could change as the corrosion level get higher (e.g. if the specimens were exposed for longer period), especially given the relationship revealed by Fig.18. Indicatively, it has been shown in a previous study investigating wires with artificial pits that the stress concentration factor increases for deeper and sharper pits. Therefore their effect on fatigue strength could be expected to be more significant as they grow [35]. Once more, these results suggest that the performance of corroded wires could be assessed by modelling the effect of corrosion through section loss and pit depth and applying an appropriate analysis method for each case. 
Test results for un-corroded wires (20 specimens) are shown in Table.6. These data were retrieved from the data base of the Public Works Research Institute in Japan [36]. The data base contains fatigue testing data of high strength galvanized steel wires used in the 1960's to construct long-span suspension bridges in Japan. Fatigue data from wires with a tensile strength of $1530 \mathrm{MPa}$, which is the closest to the $1570 \mathrm{MPa}$ grade used in this study, was used as a reference. In the data base, the fatigue test was conducted with a minimum stress of $500 \mathrm{MPa}$, stress ratio of $0.47 \sim 0.57$, and pulsating tensile load.

In analysing the test results obtained for corroded wires, specimens that fractured inside grips were excluded since it is commonly accepted that these can be influenced by the end conditions, whereas the fatigue limit was set at a value of $2 * 10^{6}$ cycles, as proposed by JSSC (Japanese Society of Steel Construction) [37]. As can be seen in Table 5, three tests were classified as 'run-outs', whereas in Table 6 for un-corroded specimens, four tests were in the same category. With regard to run-out tests, there is some debate over how to include such data, e.g. Sarkani et al. [38], since including run-outs can be problematic if they are counted as failure points or if they are ignored. On the other hand, the procedure used for determining the maximum likelihood function with limited test results can also give rise to inaccuracies Thus, based on the test data in Table.5 and 6, the $S-N$ relationships for un-corroded and corroded wires are shown in Fig.22a and Fig 22b. The former presents the results including runout specimens, which introduces an unknown degree of conservatism since it treats runouts as failure points, whereas the latter contains only the tests that are associated with true failure but reduces the sample size and the interval of stress range considered. All the $S-N$ curves shown in Fig. 22a and 22b are obtained by regression analysis, as per equations (9) to (12) below, following the procedure proposed by IIW (International Institute of Welding) [39]:

$S^{m} N=C \quad \Leftrightarrow \quad \log N=\log C-m \log S$

where $m$ is the slope and $\log C$ is the intercept and they are obtained from following equations (10) and (11).

Slope: $m=\frac{\sum_{i=1}^{n} \log S_{i} \log N_{i}-\frac{1}{n}\left(\sum_{i=1}^{n} \log S_{i}\right)\left(\sum_{i=1}^{n} \log N_{i}\right)}{\sum_{i=1}^{n}\left(\log S_{i}\right)^{2}-\frac{1}{n}\left(\sum_{i=1}^{n} \log S_{i}\right)^{2}}$

Intercept: $\log C=\frac{1}{n} \sum_{i=1}^{n} \log N_{i}+m_{n}^{-1} \sum_{i=1}^{n} \log S_{i}$

For design purposes, limits or bounds must be set to bound a certain proportion of the experimental data (usually 95\%). These bounds are often termed 'prediction limits', rather than 'confidence limits' to avoid confusion with the confidence limits on the coefficients of the regression line, and are given [39] by equation (12): 
$\log N_{p \%}^{ \pm}=(\log C-m \log S) \pm t \hat{\sigma} \sqrt{1+\frac{1}{n}+\frac{(\log S-\overline{\log S})^{2}}{\sum_{i=1}^{n}\left(\log S_{i}-\overline{\log S}\right)^{2}}}$

where $\log C$ and $m$ are the coefficients of the regression line through the $n$ data points $\left(\log S_{i}, \log N_{i}\right), \overline{\log S}$ is the mean of the $n$ values of $\log S_{i, t}$ is the appropriate percentage point of Student's $t$ distribution $t(0.05, n-2)$, with $f$ degrees of freedom, $\hat{\sigma}$ is the best estimate of variance of the data about the regression line, which is equal to the sum of squared residuals divided by the number of degrees of freedom $f$, and $\mathrm{f}$ is equal to $n-2$ in the case where the two coefficients of the regression line have both been estimated from the data.

By contrasting Fig.22a and Fig. 22b it is clear that the inclusion of runout tests has a significant influence on the estimated S-N relationships, not just at low stress range values to which these cases correspond but also on the higher stress range values (e.g. at 550MPa) where no such cases exist. Given that the percentage of runouts for both corroded and un-corroded databases is quite high (about 15\%), it was concluded that it is preferable to exclude them from the final analysis and associated comparisons.

Thus, the $S-N$ curves of the mean line (50\%) and the conservative 'design' line (95\% of points lying to the right of this line) for un-corroded and corroded wires, using the data in Fig. 22b, are found to be:

The mean line of $S$ - $N$ relationship (50\%)

For un-corroded wires $\quad S^{5.3} N=10^{19.5}$

For corroded wires $\quad S^{3.8} N=10^{15.5}$

The design line of $S-N$ relationship (95\%)

For un-corroded wires $\quad S^{5.2} N=10^{19.0}$

For corroded wires $\quad S^{3.6} N=10^{14.5}$

The slope of the design line for un-corroded wires was estimated to be $m=5.2$. This is in good agreement with the Fatigue Design Recommendation for Steel Structures, proposed by JSSC [37] were the slope is given as $m=5$. This supports the decision to exclude runout specimens from the final analysis, since their inclusion would have led to an exponent of 7.5, which is at odds with the above JSSC recommendations. Turning now to the $S$ - $N$ relationship for corroded wires, the slope of the design line was estimated to be $m=3.6$, which quantifies the degradation in fatigue strength as a result of corrosion. 
The effect of corrosion appears to be different at different stress range values. Thus, the difference between mean fatigue lives of un-corroded and corroded specimens increases as the stress range decreases. However, the variability of fatigue life is significant also increases as the stress range is reduced but does so more markedly for corroded specimens. Thus the comparative trend on the design lines is different from the trend on the mean lines. The results shown in Fig.22b are in broad agreement with the trends revealed in the study by Lan et al. [15], i.e. the slope of the $S$ - $N$ curve becomes steeper for corroded specimens compared to un-corroded specimens and the fatigue life decreases with a higher rate at lower stress ranges, even though the accelerated corrosion method used in the study by Lan et al. [15] is different.

Finally, the relationship between the corrosion area loss $A$, the corrosion pit depth $d$ and the coefficients of the $S$ $N$ relationship obtained are shown in Table.7. As more fatigue results are obtained for corroded specimens with different exposures, it might be possible to create relatively simple functional relationships between exposure time, corrosion indicators and $S-N$ coefficients.

\section{Conclusions}

The findings from this study are summarised below:

1) Various corrosion indicators which capture the spatial characteristics of the corrosion patterns can be quantified by 3D scanning techniques. Relevant correlations, e.g. the relation between corrosion area loss and corrosion depth, were demonstrated and functional relationships were determined. This suggests that the proposed scanning technique can be a useful tool in improving the fatigue assessment methods available for corroded bridge wires.

2) It was found that corrosion area loss at any given section has a higher correlation with the actual breakage position after cyclic loading compared to pit depth measured locally. This has to be tested at through further tests exposed to different time durations (and therefore resulting in different corrosion levels) as it is conjectured that pit depth might become critical at higher levels of exposure. The determination of relevant corrosion characteristics as defined by equations (3) to (8) would allow the relationship between corrosion indicators and fatigue life to be fully quantified.

3) Corrosion has an effect on fatigue life, but this effect appears to be different at different stress ranges. At any constant stress range, the variability of fatigue life (number of cycles to failure) is significant and increases for lower stress range values. This is true for both un-corroded and corroded wire specimens. 
4) The difference between the mean fatigue lives of un-corroded and corroded specimens increases as the stress range decreases. This trend is less clear on fatigue design lives due to the increased variability at lower stress ranges.

5) There is potentially a relationship between the coefficients of the $S$ - $N$ curves and the level of corrosion in bridge wires. From the present study, it was determined that the exponent $m$ reduced from about 5 to less than 4 for the design $S$ - $N$ curves for a level of corrosion that corresponds to circa $2.5 \%$ average section loss. Further tests at different corrosion levels will prove useful in extending these results to a wider range that can be used in assessing the fatigue strength of corroded wires in ageing bridges.

6) For a quantification of the relationship between exposure time, corrosion characteristics and the coefficients of $S-N$ relationships, additional specimens at different exposure times should be analysed and tested. The methodology presented in this study would allow the effective use of such a larger database in assessing fully the effect of corrosion on the fatigue life of cable wires.

Acknowledgements

In this study, the authors would like to acknowledge the support of the Daiwa Anglo-Japanese Foundation (Grant No. 5525 / 13201). In addition, the authors would like to acknowledge the anonymous reviewers for their constructive comments and suggestions.

References

1. Stahl, F. L. and Gagnon, C. P.: Cable Corrosion, ASCE Press, New York, 1996.

2. Betti, R. and Yanev, B.: Conditions of Suspension Bridge Cables, The New York City Case Study, Transportation Research Board Record, 105-112, 1999.

3. Furuya, K., Kitagawa, M., Nakamura, S. and Suzumura, K.: Corrosion Mechanism and Protection Methods for Suspension Bridge Cables, Structural Engineering International, Journal of IABSE, 10(3), 189-193, 2000.

4. Colford, B. R.: Forth Road Bridge - maintenance and remedial works, Proceedings of the Institution of Civil Engineers, Bridge Engineering 161, 125-132, 2008.

5. Cocksedge, C., Hudson, T., Urbans, B. and Barton, S.: M48 Severn Bridge - main cable inspection and rehabilitation, Proceedings of the Institution of Civil Engineers, Bridge Engineering 163, 181-195, 2010. 
6. Suzumura, K. and Nakamura, S.: Environmental Factors Affecting Corrosion of Galvanized Steel Wires, Journal of Materials in Civil Engineering, ASCE, 1-7, 2004.

7. Barton, S.C., Vermaas G.W., Duby P.F., West A.C., and Betti R., Accelerated Corrosion and Embrittlement of High Strength Bridge Wire, Journal of Materials in Civil Engineering, Vol. 12, No. 1, Feb. 2000, pp. 33-38.

8. Nakamura, S. and Suzumura, K.: Hydrogen embrittlement and corrosion fatigue of corroded bridge wires, Journal of Constructional Steel Research, 65, 269-277, 2009.

9. Li, H., Lan, C. M., Ju, Y. and Li, D. S.: Experimental and Numerical Study of the Fatigue Properties of Corroded Parallel Wire Cables, Journal of Bridge Engineering, ASCE, 17(2), 211-220, 2012.

10. Nakamura, S. and Suzumura, K.: Experimental Study on Fatigue Strength of Corroded Bridge Wires, Journal of Bridge Engineering, ASCE, 18(3), 200-209, 2013.

11. Miyachi, K., Nakamura, S. and Chryssanthopoulos, M.K.: Risk assessment of Corroded Bridge Wires using 3D Laser Scanner, 19th IABSE Congress, 98-106, 2016.

12. Jiang, C., Wu, C. and Jiang, X.: Experimental study on fatigue performance of corroded high-strength steel wires used in bridges, Construction and Building Materials, 187, 681-690, 2018.

13. Xu, Y., Li, H., Li, S., Guan, X. and Lan, C.: 3-D modelling and statistical properties of surface pits of corroded wire based on image processing technique, Corrosion Science, Vol.111, 275-287, 2016.

14. Zheng, Y. and Wang, Ying.: Damage evolution simulation and life prediction of high-strength steel wire under the coupling of corrosion and fatigue, Corrosion Science, Vol.164, 1-16, 2019.

15. Lan, C., Xu, Y., Liu, C., Li, H. and Spencer Jr., B.F.: Fatigue life prediction for parallel-wire stay cables considering corrosion, International Journal of Fatigue, 114, 81-91, 2018.

16. Tarui, T., Maruyama, N., Eguchi, T. and Konno, S.: Development of High Strength Galvanized Steel Wire for Bridge Cable: Cable-Supported Bridges-Challenging Technical Limits, IABSE Symposium Report, 33-40, 2001.

17. Oki, Y., Ibaraki, N., Kaiso, M. and Makii, K.: Development of 200kgf/mm² Grade High-strength Zincgalvanized Wire, Kobe steel engineering reports, Vol.49, No.2, 1999.

18. Farquhar D.J.: Cable stayed bridges: ICE manual of bridge engineering, 2nd edition, 357-381, 2008.

19. Jones V. and Howells J.: Suspension bridges: ICE manual of bridge engineering, 2nd edition, 383-419, 2008. 
20. NCHRP Report 534: Guidelines for Inspection and Strength Evaluation of Suspension Bridge Parallel Wire Cable, 17-25, 2004.

21. Furuya, K., Kitagawa, M., Nakamura, S., Suzumura, K. and Seiryu, M.: Corrosion performance evaluation of suspension bridge cable corrosion protection methods by field exposed tests, Journal of JSCE, No.637/VI-45, 15-28, 1999.

22. Betti, R., Khazem, D., Carlos, M., Gostautas, R., and Virmani, Y. P.: Corrosion Monitoring Research for City of New York Bridges, Publication No. FHWA-HRT-14-023, 2014.

23. Suzumura, K.: Study on corrosion mechanism of suspension bridge cable and development of anticorrosion technology, Doctoral thesis, Tokai University, pp. 21-90, 2004.

24. Colford, B.: The maintenance of long span bridges, Heriot-Watt Industry Day 'Sustainable development - Infrastructure solutions and challenges', 2013. https://docplayer.net/18903659-The-maintenance-oflong-span-bridges-barry-colford-chief-engineer-bridgemaster-forth-road-bridge.html, (2020.07.16).

25. ISO. 9227:1990, Corrosion tests in artificial atmospheres - Salt spray tests, ISO,1990.

26. Llano, L., Chryssanthopoulos, M.K., Hagen-Zanker, A. and Rafiq, M.I.: Stochastic modelling of chloride-induced pitting corrosion reinforcement bars in concrete, Proceedings of the 11th International Conference on Structural Safety and Reliability, ICOSSAR, 2013.

27. Means, B.K., Bowles, C., McCuistion, A. and King, C.: Three-Dimensional Digital Data Collection for Artifact Analysis and Interpretation, Legacy Project \#11-334, 1-168, 2013.

28. Suzumura, K., Nakamura, S. and Tarui, T.: A consideration on broken steel wires of suspension bridge cables, Journal of JSCE, No.738/I-64, 297-306, 2003.

29. Umbach, D. and Jones, N. K.: A Few Methods for Fitting Circles to Data, IEEE Transactions on Instrumentation and Measurement, Vol. 52, No. 6, 1881-1885, 2003.

30. Mitamura, T., Nakai, H., Watanabe, E. and Sugii, K.: Recent topic on bridge cables and future prospects, JSCE, No.444, VI-16, 97-106, 1992.

31. Yasuda, M. and Yoshida, Y.: Design and Construction of Steel Structure of Akashi Kaikyo Bridge, Journal of Japan Welding Society, Vol.60, No.8, 20-28, 1991.

32. Japanese Society of Steel Construction: Cable-stayed Steel Bridge, Steel Structures Series 5, 40-45, 1990.

33. Nakamura, S. and Fujii, M.: Comparison of Cable Safety Factors of Steel Cable-Stayed Bridges and Extradosed Bridges, JSCE Journal of Structural Engineering, Vol.53A, 957-967, 2007. 
34. Li, S., Wei, S., Bao,Y. and Li, H..: Condition assessment of cables by pattern recognition of vehicleinduced cable tension ratio, Engineering Structures, Vol.155, pp. 1-15, 2018.

35. Miyachi, K. and Nakamura, S.: Experimental and analytical study on fatigue strength and stress concentration of corroded bridge wires, Bridge Structures, Vol.12, pp.21-31, 2016.

36. Public Works Research Institute, Production test report of high strength galvanized steel wire for long suspension bridge parallel cable II, No.60, Japan, 1965.

37. Japanese Society of Steel Construction: Guidelines of Fatigue Design of Steel Structures, Gihodo, 1998.

38. Sarkani, S., Mazzuchi, T.A., Lewandowski, D. and Kihl, D.P.: Runout analysis in fatigue investigation, Engineering Fracture Mechanics, Vol.74, pp.2971-2980, 2007.

39. Schneider, C. R. A. and Maddox, S. J.: Best practice guide on statistical analysis of fatigue data, International Institute of Welding TWI statistics report, 1-20, 2003. 
Table.1: Chemical composition of galvanized steel wires (mass \%)

\begin{tabular}{cccc}
\hline Strength grade of wire & $\mathrm{C}$ & $\mathrm{Si}$ & $\mathrm{Mn}$ \\
\hline $5 \mathrm{~mm}-1570 \mathrm{MPa}[1,2]$ & $0.75 \sim 0.80$ & $0.12 \sim 0.32$ & $0.60 \sim 0.90$ \\
$5.03 \mathrm{~mm}-1530 \mathrm{MPa}[8]$ & 0.79 & 0.28 & 0.50 \\
$5.15 \mathrm{~mm}-1570 \mathrm{MPa}$ [This study] & $0.86-0.89$ & $0.21 \sim 0.27$ & $0.83 \sim 0.85$
\end{tabular}

Table.2 Comparison of wire corrosion classification schemes

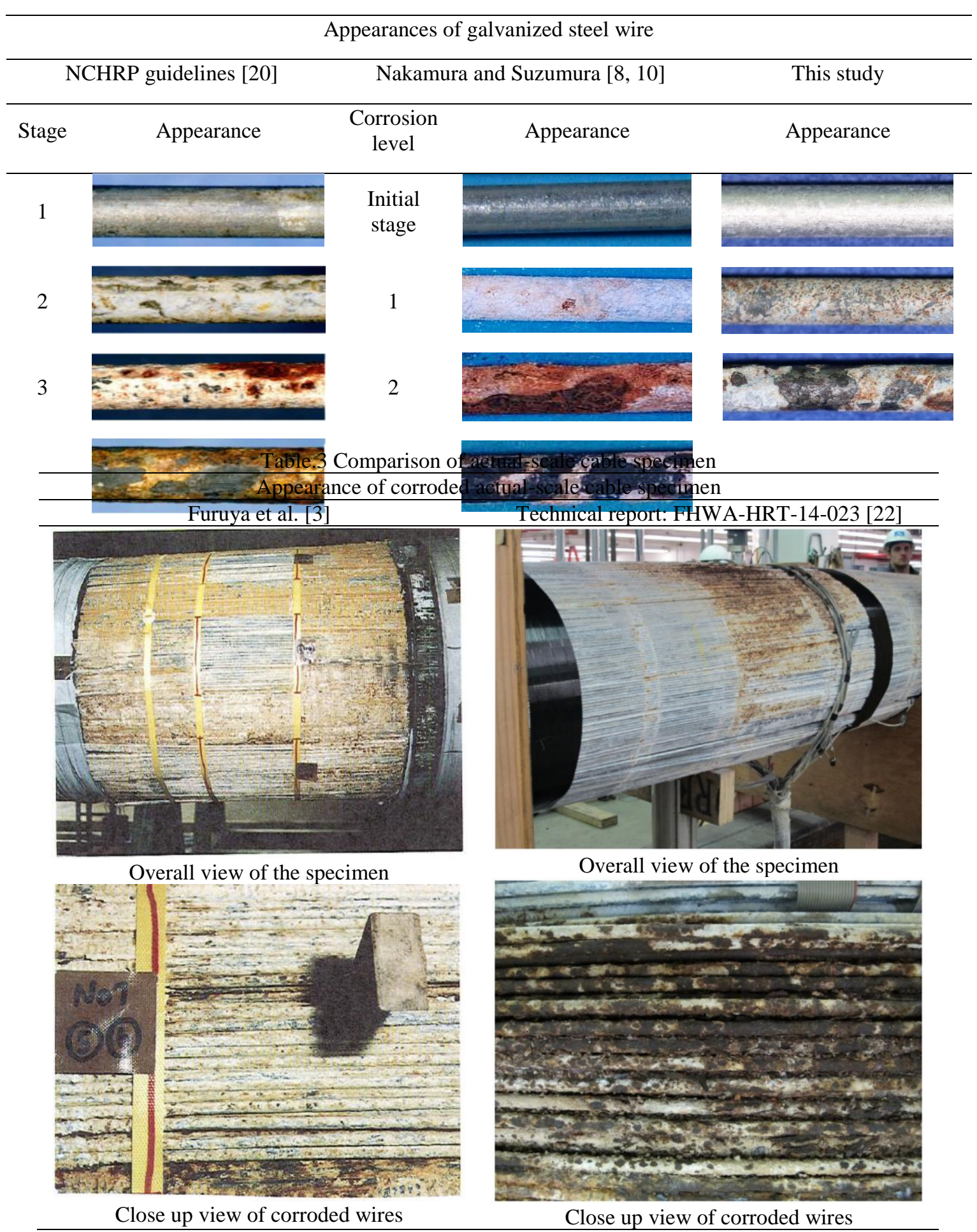


Table.4 Comparison of actual cable

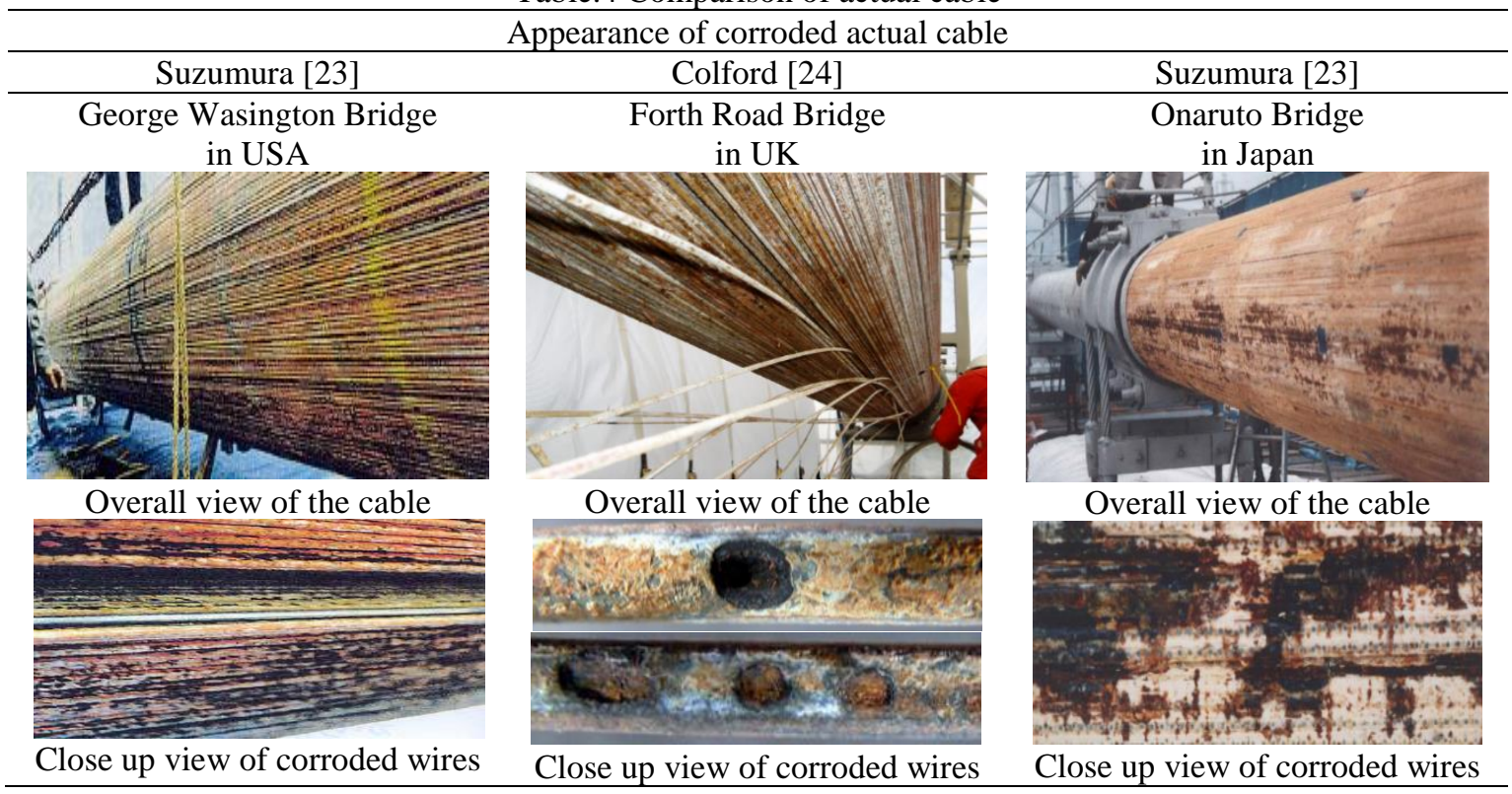

Table.5 Wire properties and design working stresses in suspension bridges

\begin{tabular}{lccccc}
\hline Bridge name & $\begin{array}{c}\text { Year of } \\
\text { Completion }\end{array}$ & Country & $\begin{array}{c}\text { Wire diameter } \\
\text { (Unit: mm) }\end{array}$ & $\begin{array}{c}\text { Tensile strength } \\
\text { (Unit: MPa) }\end{array}$ & $\begin{array}{c}\text { Design working stress } \\
\text { (Unit: MPa) }\end{array}$ \\
\hline Forth Road & 1964 & UK & 4.98 & 1520 & 608 \\
Severn & 1966 & UK & 4.98 & 1520 & 686 \\
Kanmon & 1973 & Japan & 5.04 & 1570 & 569 \\
Humber & 1981 & UK & 5.00 & 1570 & 686 \\
Innoshima & 1983 & Japan & 5.17 & 1570 & 549 \\
Oonaruto & 1985 & Japan & 5.37 & 1570 & 628 \\
Akashi-Kaikyo & 1998 & Japan & 5.23 & 1770 & 804
\end{tabular}

Table.6 Fatigue loading regime

\begin{tabular}{cccc}
\hline$\sigma_{\min }(\mathrm{MPa})$ & $R=\sigma_{\min } / \sigma_{\max }(\mathrm{MPa})$ & $\Delta \sigma=\sigma_{\max }-\sigma_{\min }(\mathrm{MPa})$ & Reference \\
\hline varies $(180 \sim 347)$ & 0.4 & 270 to 520 & {$[12]$} \\
500 & varies $(0.45-0.71)$ & 200 to 600 & {$[10]$} \\
varies $(335 \sim 670)$ & 0.5 & 335 to 670 & {$[15]$} \\
500 & varies $(0.48-0.55)$ & 400 to 550 & this study \\
\hline
\end{tabular}


Table.7 Test results for corroded wires (30 specimens)

\begin{tabular}{|c|c|c|c|c|c|c|c|c|c|}
\hline no. & $\begin{array}{l}\text { Average } \\
\text { area loss }\end{array}$ & $\begin{array}{c}\text { Maximum } \\
\text { area loss }\end{array}$ & $\begin{array}{l}\text { Average } \\
\text { pit depth }\end{array}$ & $\begin{array}{l}\text { Maximum } \\
\text { pit depth }\end{array}$ & $\begin{array}{l}\text { Stress } \\
\text { range }\end{array}$ & $\begin{array}{l}\text { Number of } \\
\text { cycles to } \\
\text { failure }\end{array}$ & $\begin{array}{l}\text { Location } \\
\text { of } A_{\max }\end{array}$ & $\begin{array}{l}\text { Location } \\
\text { of } d_{\max }\end{array}$ & $\begin{array}{l}\text { Failure } \\
\text { location }\end{array}$ \\
\hline & $A_{\text {ave }}(\%)$ & $A_{\max }(\%)$ & $d_{\text {ave }}(\mathrm{mm})$ & $d_{\max }(\mathrm{mm})$ & $S(\mathrm{MPa})$ & $N$ (cycles) & $L_{A}(\mathrm{~mm})$ & $L_{d}(\mathrm{~mm})$ & $L_{F}(\mathrm{~mm})$ \\
\hline- & 2.9 & 4.5 & 0.110 & 0.170 & 550 & 83,597 & 56 & 9 & Grip \\
\hline - & 4.0 & 7.5 & 0.132 & 0.237 & 550 & 92,798 & 90 & 90 & Grip \\
\hline - & 3.4 & 9.3 & 0.123 & 0.291 & 550 & 80,267 & 35 & 57 & Grip \\
\hline 1 & 3.6 & 10.2 & 0.128 & 0.254 & 550 & 81,104 & 90 & 2 & 41 \\
\hline- & 2.8 & 8.5 & 0.132 & 0.288 & 550 & 98,718 & 49 & 97 & Grip \\
\hline- & 3.2 & 7.7 & 0.116 & 0.235 & 550 & 73,265 & 3 & 50 & Grip \\
\hline 2 & 2.4 & 8.0 & 0.109 & 0.262 & 550 & 92,613 & 8 & 80 & 7 \\
\hline 3 & 2.6 & 5.7 & 0.119 & 0.240 & 500 & 126,833 & 87 & 85 & 66 \\
\hline 4 & 1.6 & 3.8 & 0.110 & 0.154 & 500 & 125,519 & 77 & 78 & 5 \\
\hline- & 2.1 & 4.2 & 0.108 & 0.170 & 500 & 102,312 & 82 & 0 & Grip \\
\hline- & 2.6 & 3.8 & 0.113 & 0.181 & 500 & 136,396 & 66 & 66 & Grip \\
\hline 5 & 3.0 & 6.1 & 0.115 & 0.247 & 500 & 104,464 & 29 & 55 & 67 \\
\hline 6 & 0.8 & 5.6 & 0.113 & 0.216 & 500 & 140,846 & 35 & 79 & 35 \\
\hline 7 & 1.2 & 7.1 & 0.123 & 0.234 & 500 & 113,492 & 89 & 89 & 89 \\
\hline 8 & 5.6 & 10.8 & 0.200 & 0.405 & 450 & 177,657 & 72 & 46 & 71 \\
\hline 9 & 4.3 & 8.7 & 0.179 & 0.364 & 450 & 299,358 & 6 & 63 & 6 \\
\hline 10 & 3.6 & 14.0 & 0.179 & 0.342 & 450 & 163,634 & 90 & 88 & 90 \\
\hline 11 & 1.4 & 3.6 & 0.100 & 0.162 & 450 & 157,741 & 7 & 26 & 85 \\
\hline 12 & 0.8 & 2.3 & 0.093 & 0.161 & 450 & 203,429 & 72 & 79 & 81 \\
\hline 13 & 2.3 & 6.9 & 0.135 & 0.309 & 450 & 164,056 & 94 & 1 & 91 \\
\hline 14 & 4.6 & 14.1 & 0.161 & 0.296 & 400 & 131,416 & 87 & 87 & 87 \\
\hline 15 & 1.7 & 5.9 & 0.122 & 0.225 & 412 & $1,132,804$ & 77 & 77 & 77 \\
\hline- & 1.8 & 6.4 & 0.110 & 0.271 & $350 / 500$ & $1,095,358$ & 48 & 47 & *Varying $S$ \\
\hline- & 2.3 & 4.5 & 0.099 & 0.164 & 400 & $10,064,209$ & 54 & 56 & Run-out \\
\hline 16 & 2.1 & 11.2 & 0.130 & 0.380 & 400 & 22,459 & 70 & 49 & 53 \\
\hline 17 & 1.6 & 10.3 & 0.106 & 0.255 & 400 & 261,380 & 68 & 67 & 67 \\
\hline- & 3.0 & 7.8 & 0.137 & 0.275 & 400 & $8,768,902$ & 38 & 88 & Run-out \\
\hline- & 3.0 & 7.1 & 0.142 & 0.290 & 400 & $7,151,932$ & 61 & 23 & Grip \\
\hline- & 2.8 & 9.1 & 0.117 & 0.275 & 400 & $3,903,021$ & 77 & 42 & Run-out \\
\hline 18 & 3.4 & 9.7 & 0.135 & 0.225 & 400 & 290,602 & 30 & 55 & 34 \\
\hline Ave. & 2.7 & 7.5 & 0.127 & 0.253 & - & - & - & - & - \\
\hline S.D. & 1.1 & 2.9 & 0.025 & 0.066 & - & - & - & - & - \\
\hline C.V. & 0.4 & 0.4 & 0.197 & 0.262 & - & - & - & - & - \\
\hline
\end{tabular}

* This specimen is excluded from $S-N$ analysis as it was tested under two substantially different stress ranges. 
Table. 8 Test results for un-corroded wires (24 specimens)

\begin{tabular}{cccc}
\hline no. & $\begin{array}{c}\text { Stress } \\
\text { range }\end{array}$ & $\begin{array}{c}\text { Number of } \\
\text { cycles to } \\
\text { failure }\end{array}$ & Failure \\
& $S(\mathrm{MPa})$ & $N$ (cycles) & \\
\hline 1 & 568 & 105,000 & Centre \\
2 & 568 & 114,000 & Centre \\
3 & 561 & 140,000 & Centre \\
4 & 550 & 92,798 & Centre \\
5 & 550 & 80,267 & Centre \\
6 & 550 & 83,597 & Centre \\
7 & 550 & 98,718 & Centre \\
8 & 550 & 73,265 & Centre \\
9 & 537 & 108,000 & Centre \\
10 & 512 & 204,000 & Centre \\
11 & 506 & 171,000 & Centre \\
12 & 498 & 166,000 & Centre \\
13 & 490 & 118,000 & Centre \\
14 & 463 & 264,000 & Centre \\
15 & 457 & 421,000 & Centre
\end{tabular}

Table.9 Comparison of corrosion indicators and $S-N$ coefficients for wire specimens

\begin{tabular}{ccccc}
\hline $\begin{array}{c}\text { Condition of } \\
\text { wires }\end{array}$ & $\begin{array}{c}A_{\text {ave }} \\
(\%)\end{array}$ & $\begin{array}{c}d_{\max } \\
(\mathrm{mm})\end{array}$ & $\begin{array}{c}\text { Slope } m \\
\text { mean (design) }\end{array}$ & $\begin{array}{c}\text { Intercept } C \\
\text { mean (design) }\end{array}$ \\
\hline $\begin{array}{c}\text { Un-corroded } \\
\text { Corroded }\end{array}$ & 0.0 & 0.000 & $5.3(5.2)$ & $10^{19.5}\left(10^{19}\right)$ \\
& $1.6 \sim 3.8$ & $0.187 \sim 0.319$ & $3.8(3.6)$ & $10^{15.5}\left(10^{14.5}\right)$ \\
\hline
\end{tabular}




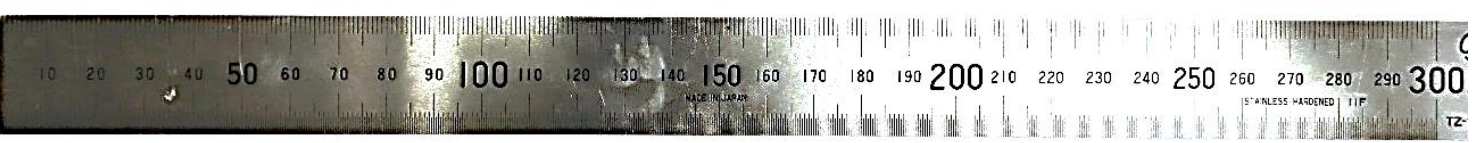

Fig.1 High-strength galvanized steel wire specimen

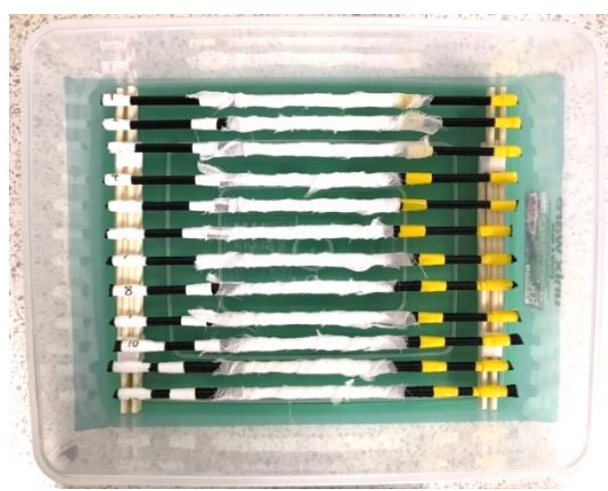

(a) Specimens were wrapped with wet-gauze in a sealed plastic box with the lid

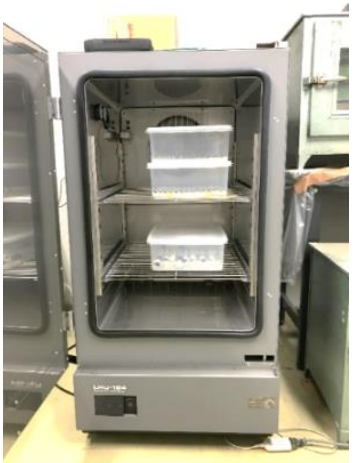

(b) Specimens were kept in the thermostat at $40^{\circ} \mathrm{C}$ for 150 days

Fig.2 Accelerated corrosion method

(a) Un-corroded wire

(b) Corroded wire after 30days of the test

(c) Corroded wire after 90days of the test

(d) Corroded wire after 150days of the test

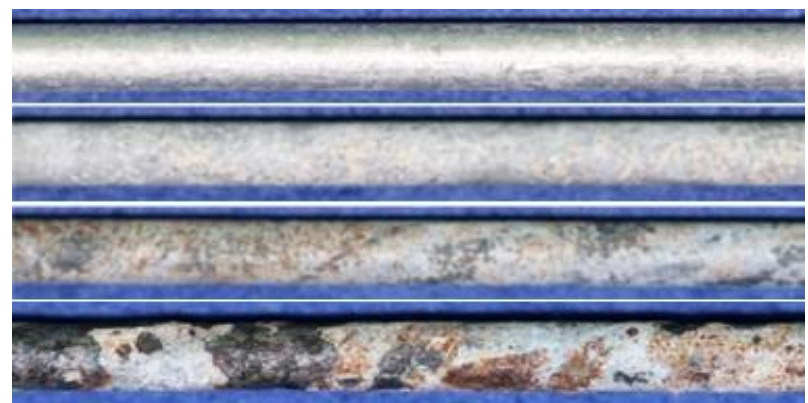

Fig.3 Un-corroded and corroded wire specimens

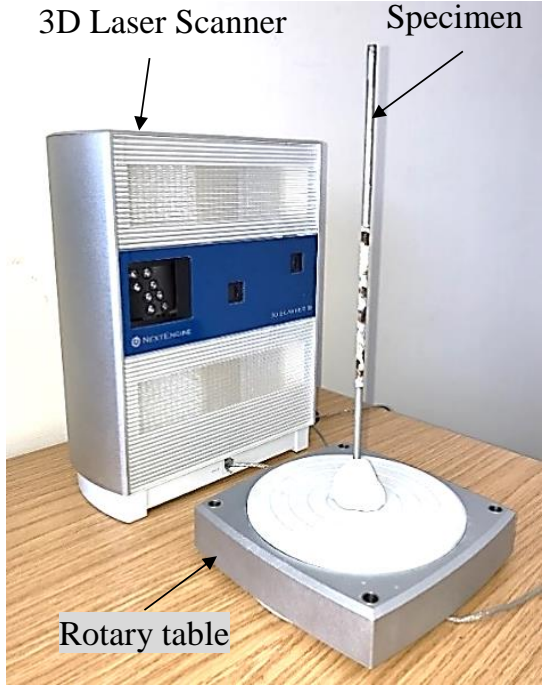

Fig.4 3D laser scanner

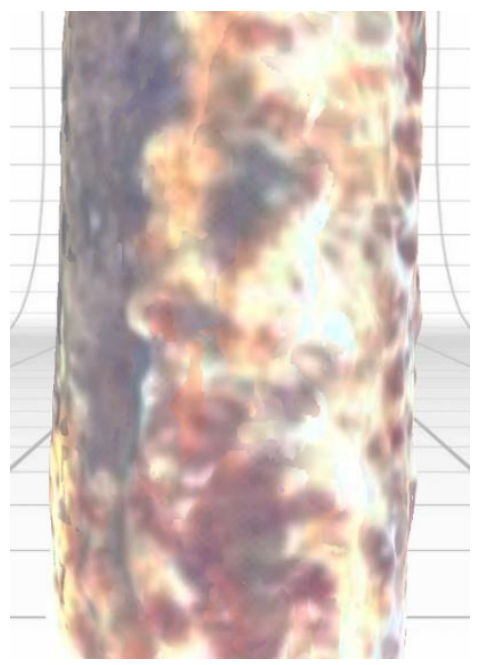

(a) Picture data

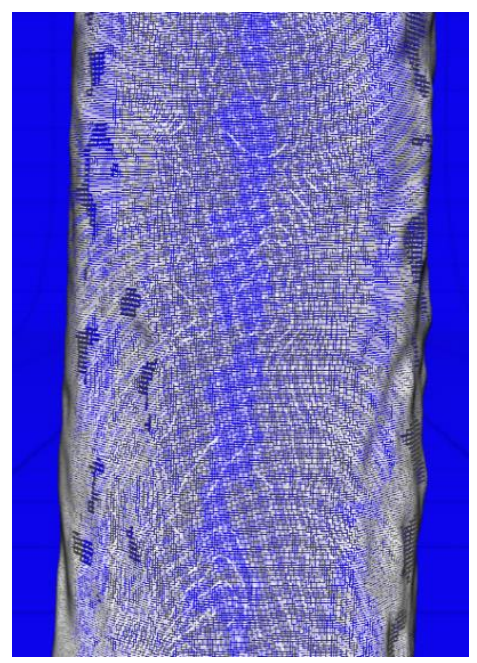

(b) Point cloud data

Fig.5 Scan data 


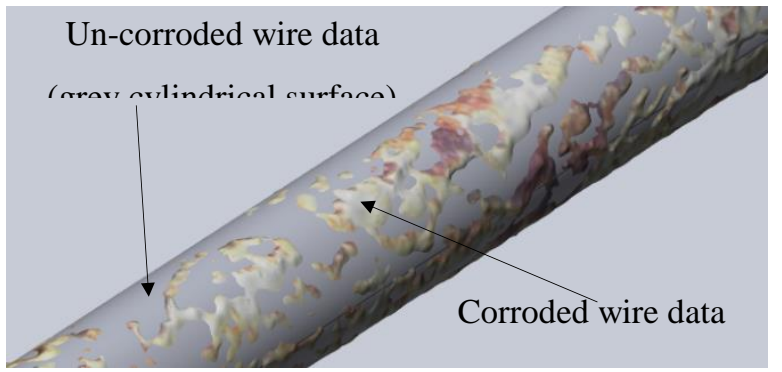

(a) Image after matching axis of un-corroded wire with corroded wire data

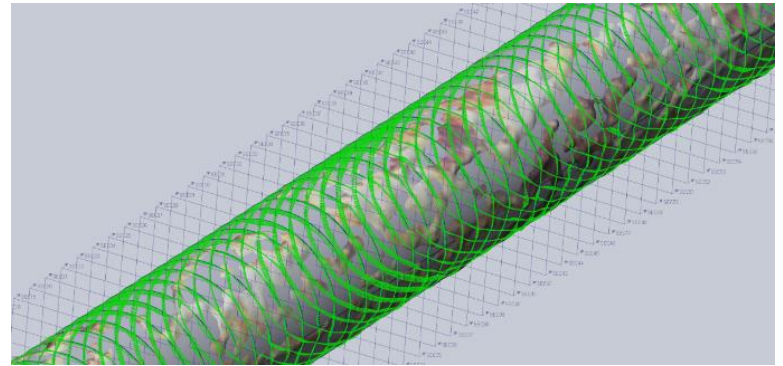

(b) Corroded length divided into sections ( $1 \mathrm{~mm}$ pitch)

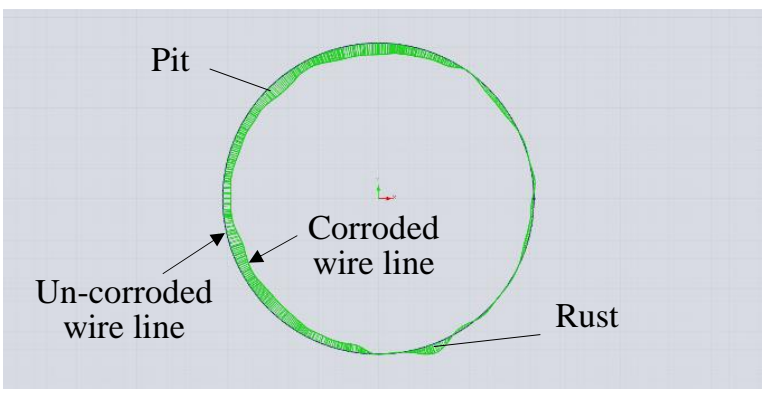

(c) Corrosion pattern at a cross-section

Fig.6 Visualization of scanned point cloud data

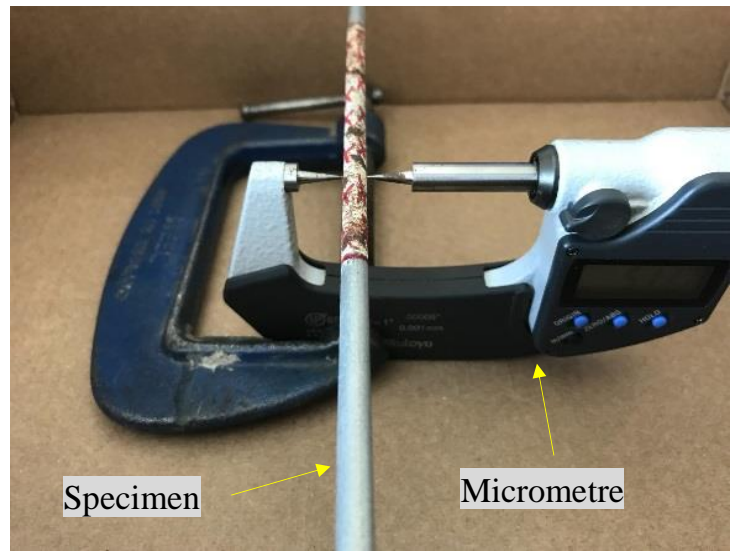

(a) Manual measurement

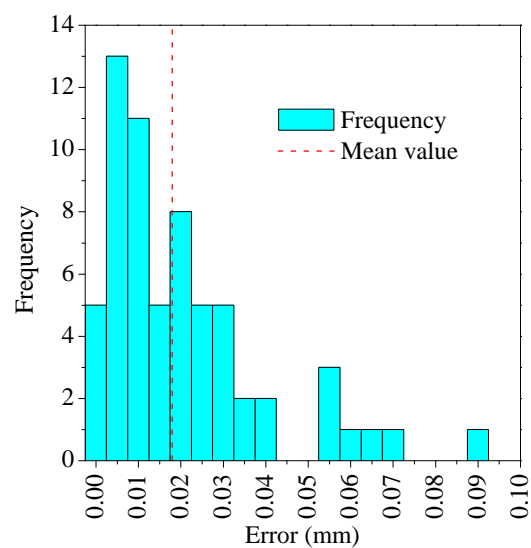

(b) Histogram of absolute error

Fig.7 Comparison between manual and virtual calliper

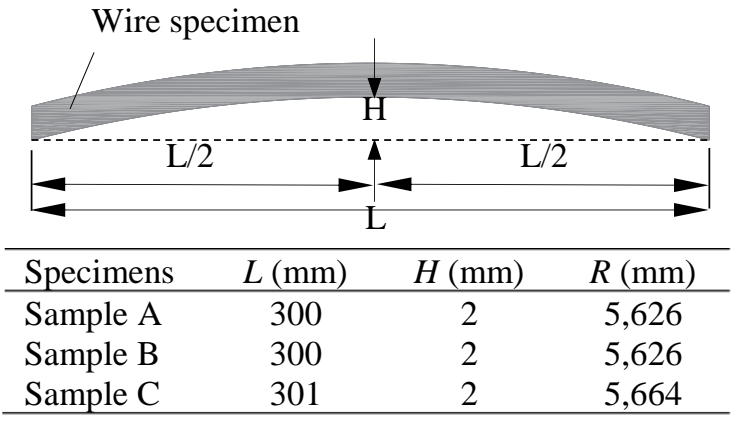

Fig.8 Measurement of curvature 


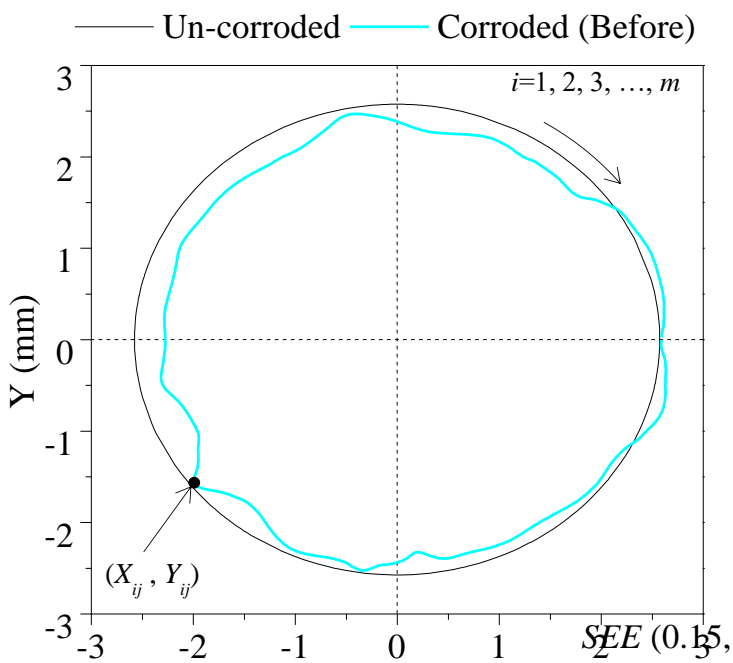

(a) Before best-fit $X_{\text {afmonydyis at }} \mathrm{j}$ section
- Un-corroded — Corroded (After)

- Corroded (Before)

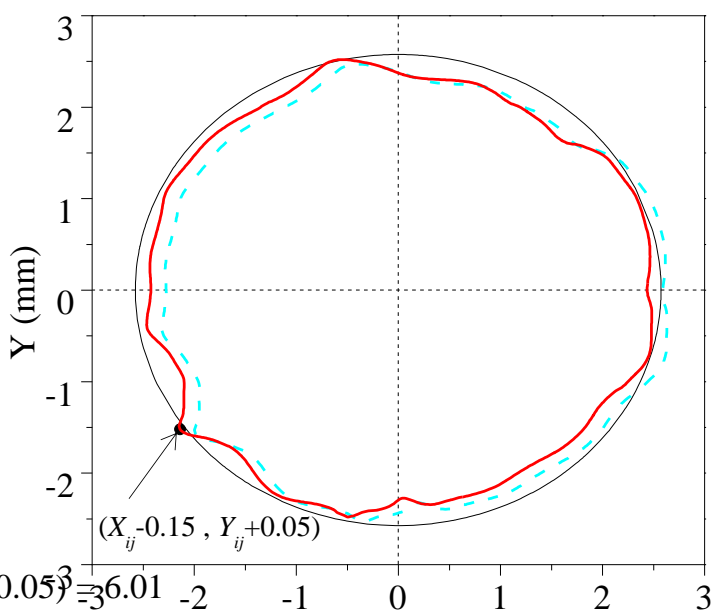

(b) After best-fit XXadrysts at $\mathrm{j}$ section

Fig.9 Fitting best-fit circle to scanned data

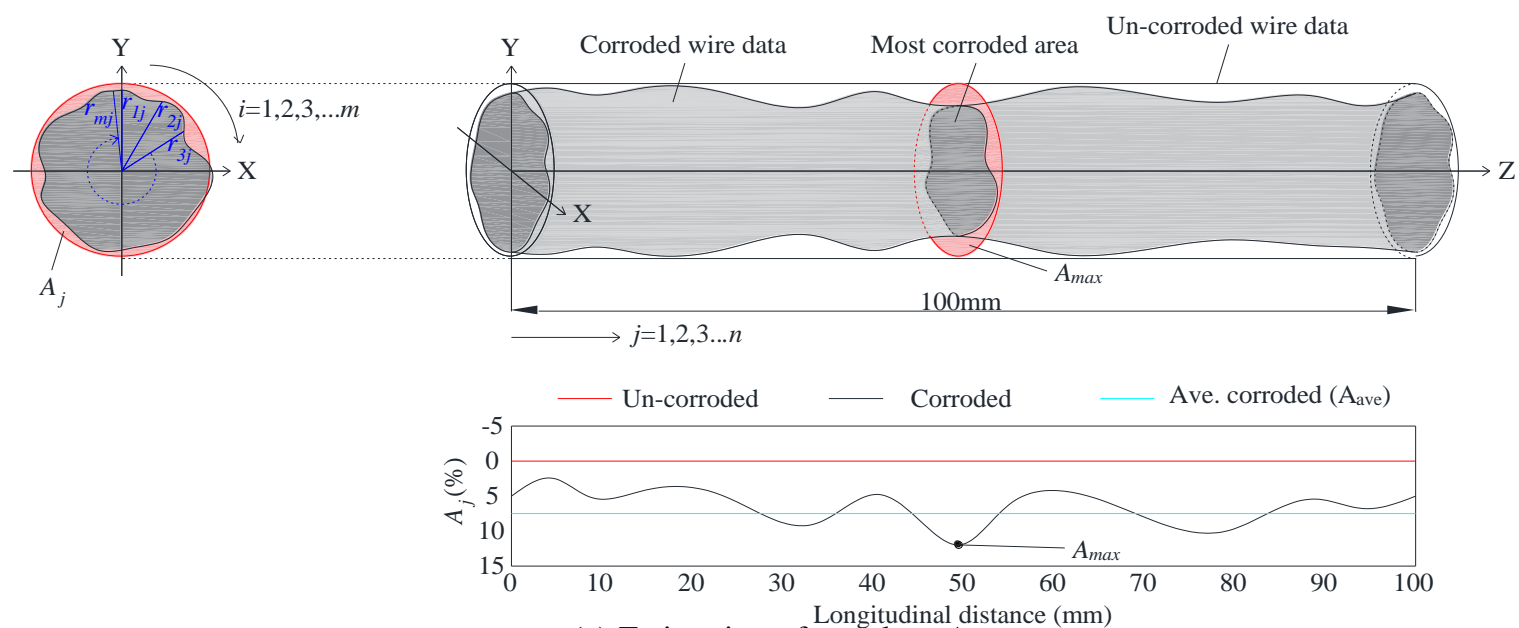

(a) Estimation of area loss $A_{j}$
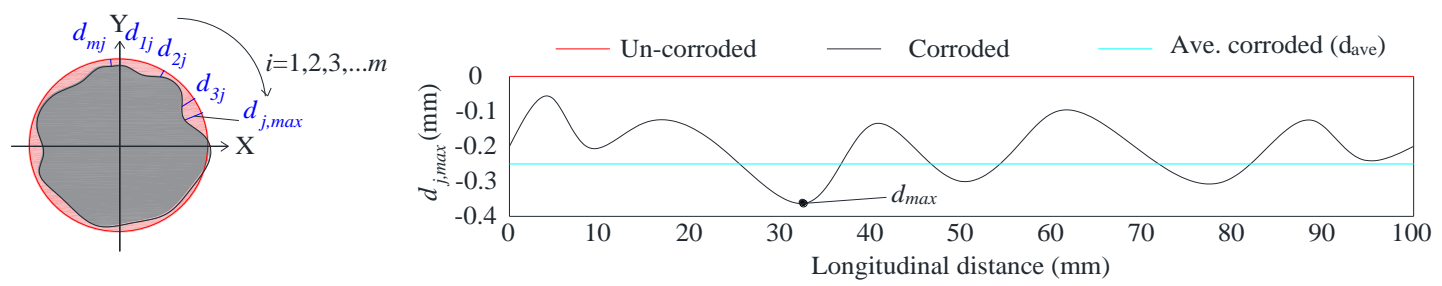

(b) Estimation of pit depth $d_{\max }$

Fig.10 Method used for estimating corrosion indicators 
300

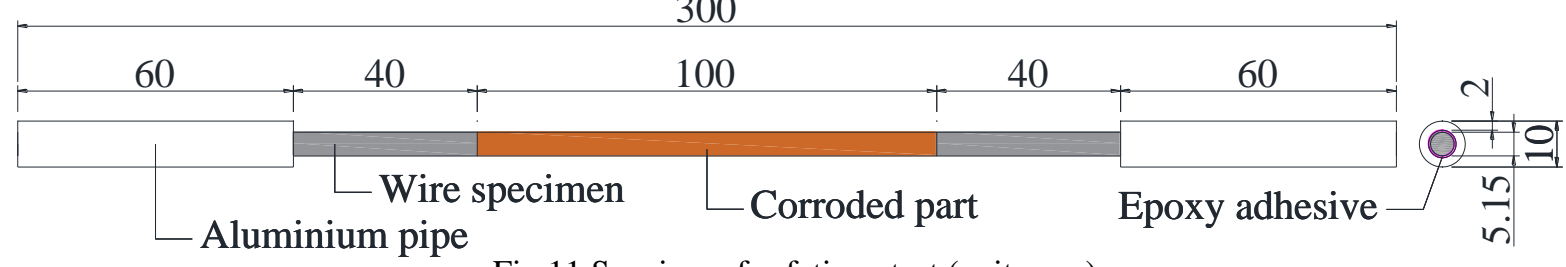

Fig.11 Specimen for fatigue test (unit: $\mathrm{mm}$ )
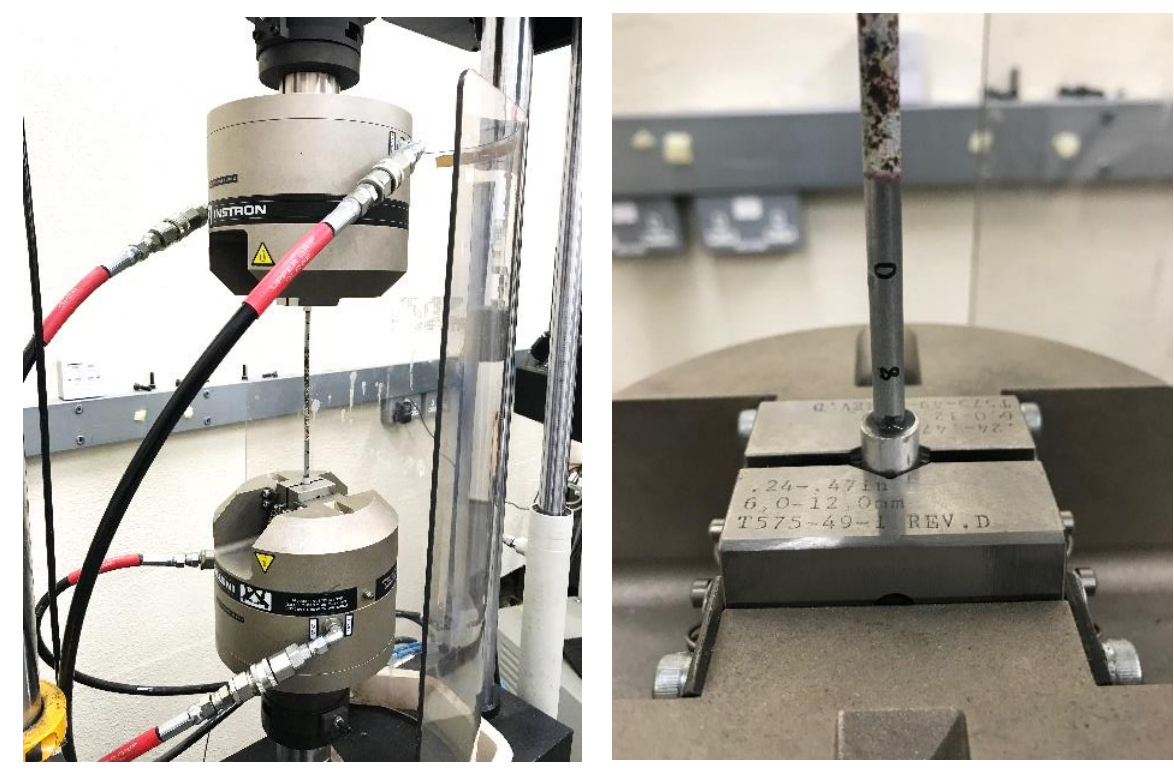

Fig.12 Fatigue testing rig with detail showing grips 


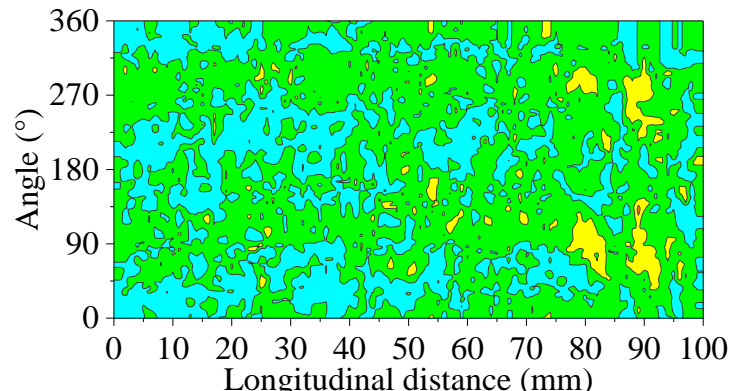

(a) Specimen no.7

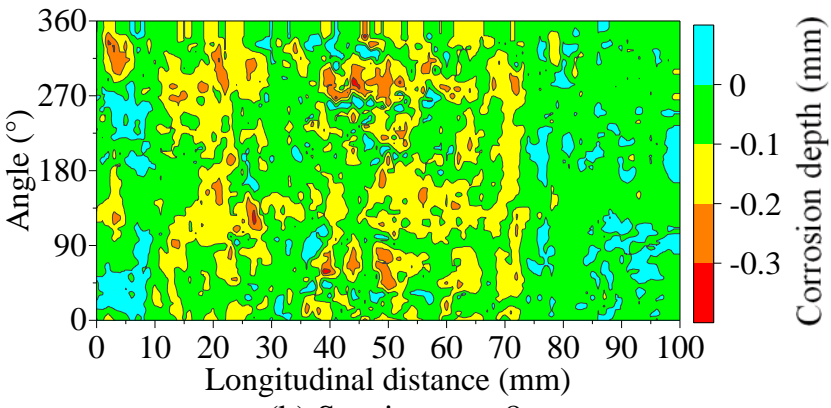

(b) Specimen no. 8

Fig.13 Contour of corroded surface roughness

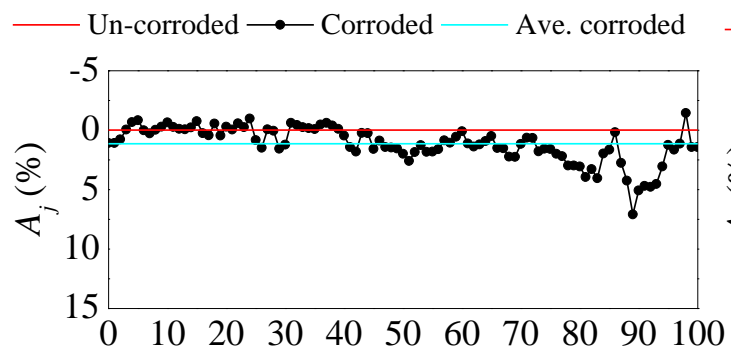

Londitudinal distance ( $\mathrm{mm}$ )

(a) Specimen no.7

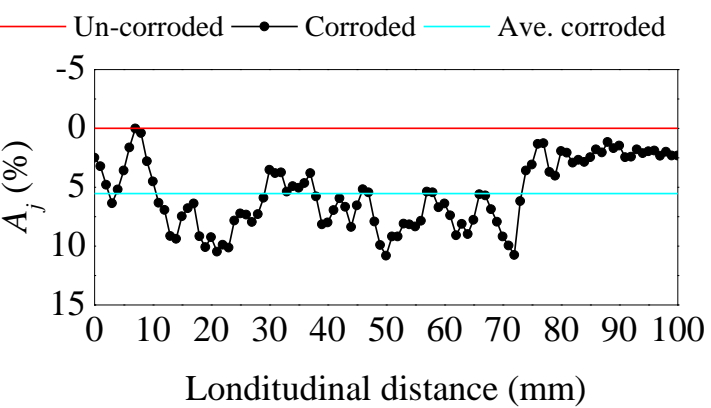

(b) Specimen no. 8

Fig. 14 Sectional area loss $A_{j}$

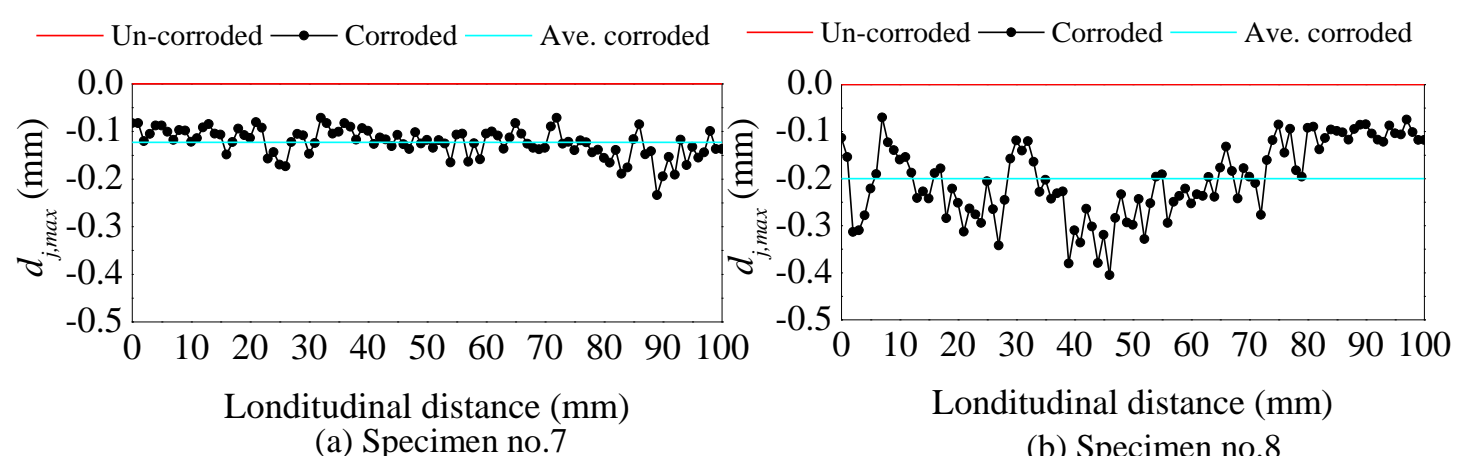

(a) Specimen no.7

(b) Specimen no. 8

Fig. 15 Maximum pit depth $d_{j, \max }$ 


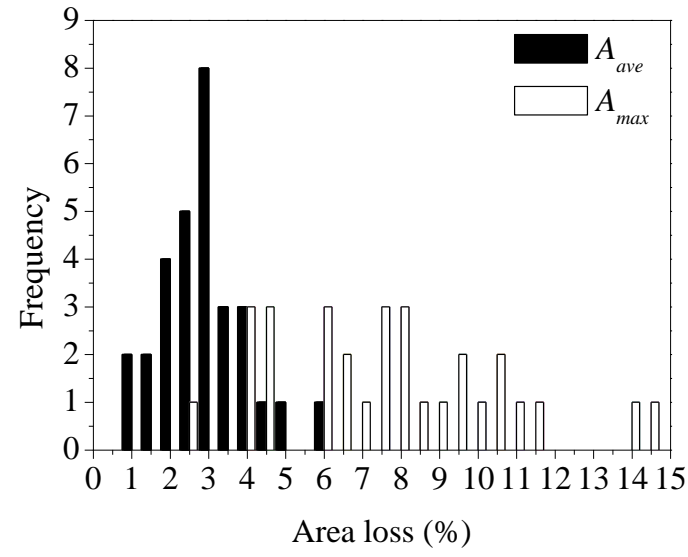

Fig.16 Area loss histogram (30 specimens)

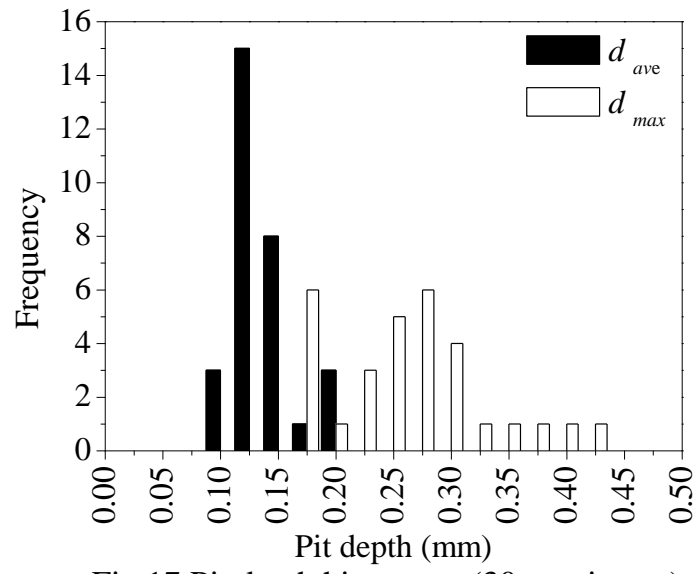

Fig.17 Pit depth histogram (30 specimens)

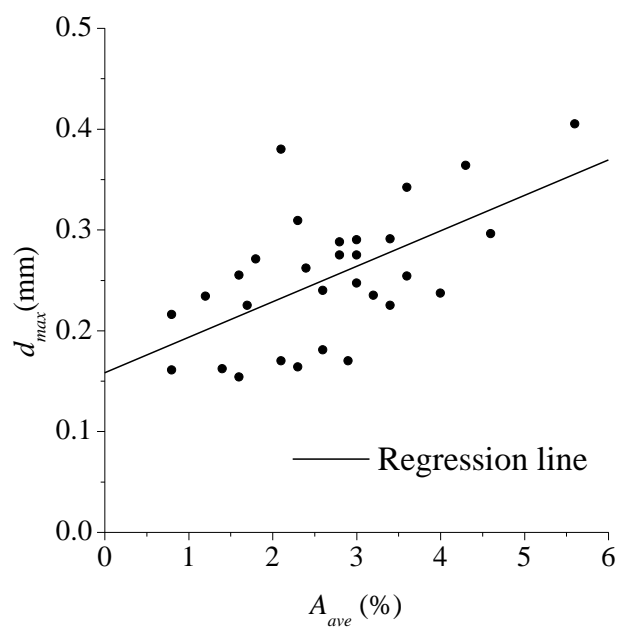

Fig.18 Relationship between $A_{\text {ave }}$ and $d_{\max }$ (30 specimens)

$$
\rho\left(A_{\text {ave }}, d_{\text {max }}\right)=0.59
$$




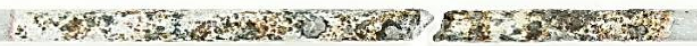

T. GR

3y.

Fig.19 Breakage wires after the fatigue test

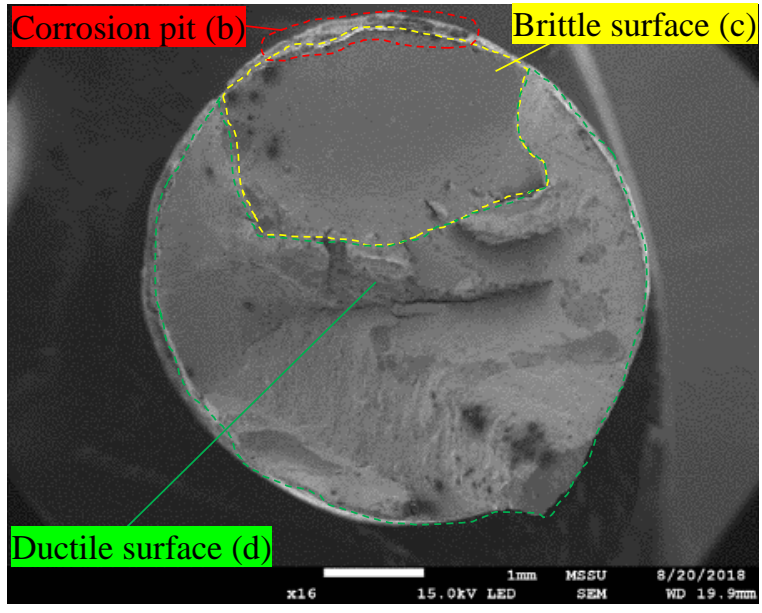

(a) Whole photo

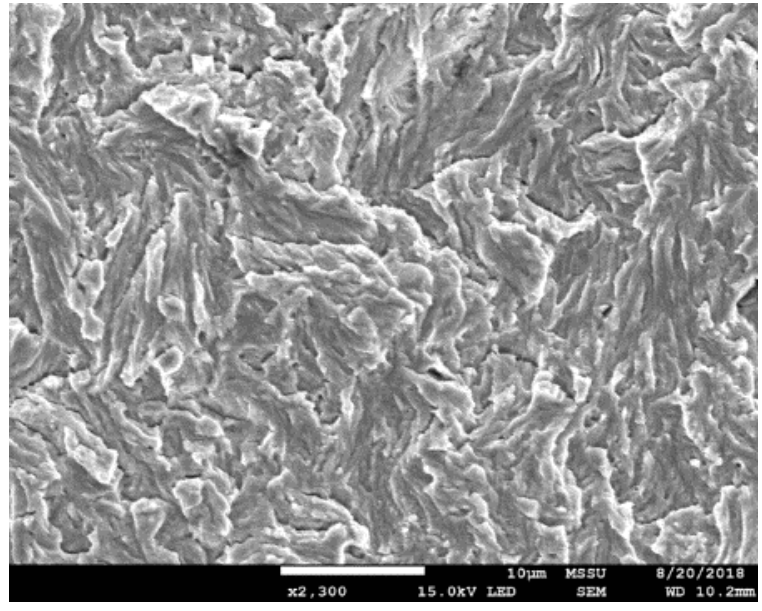

(c) Close up photo of brittle surface (feather marking)

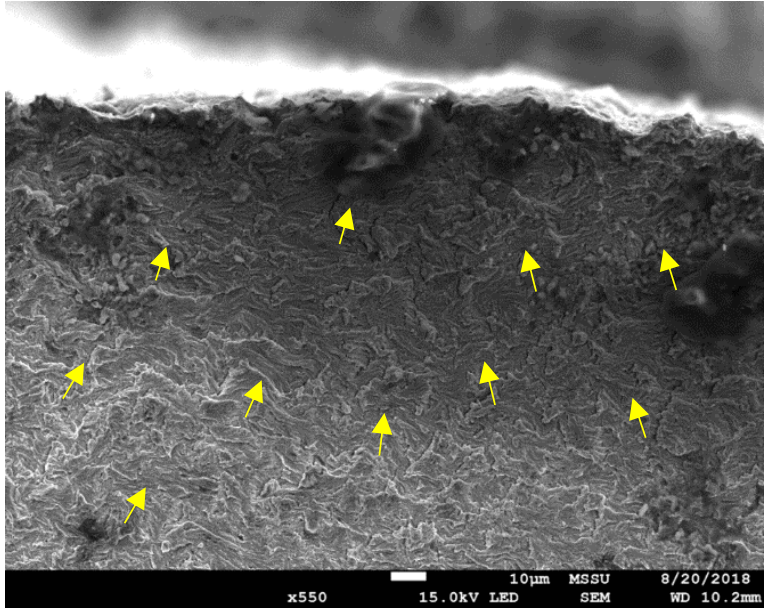

(b) Close up photo of corrosion pit part

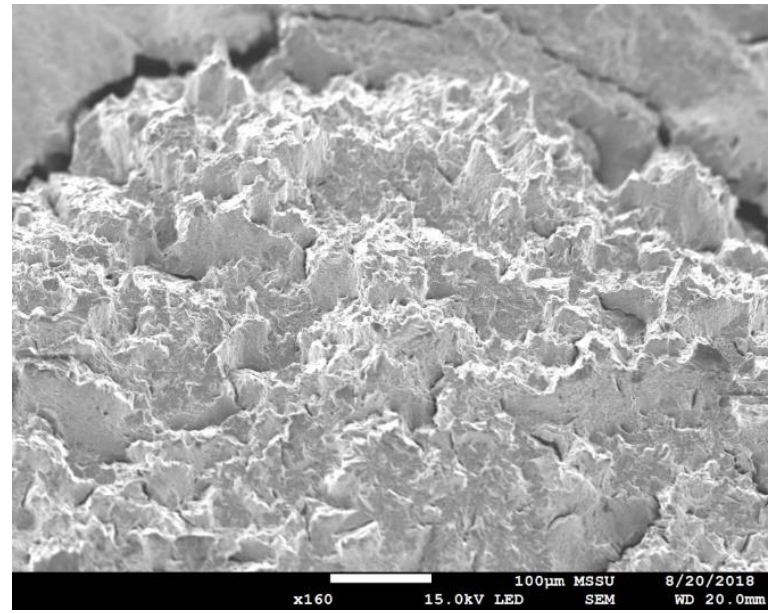

(d) Close up photo of ductile surface (Dimple)

Fig.20 Fracture surfaces 


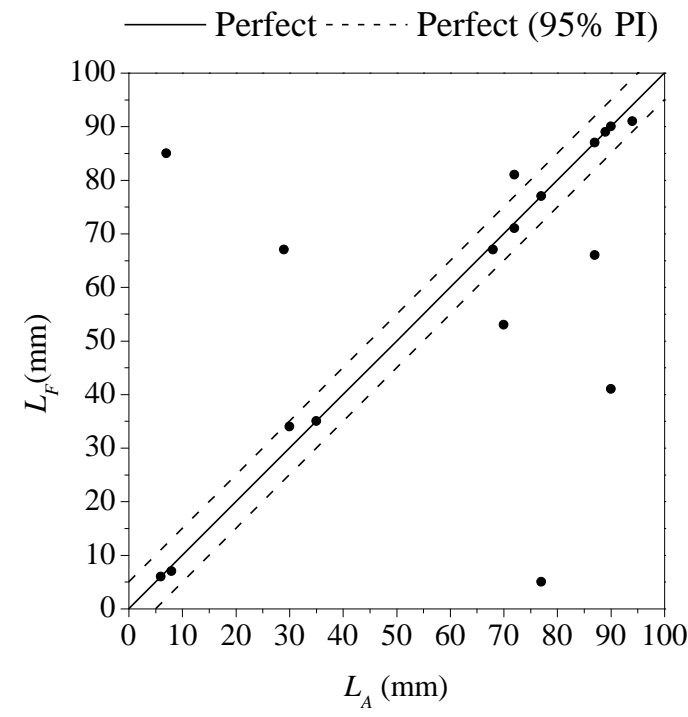

Fig.21a $L_{F}$ vs $L_{A}(18$ specimens $)$

$$
\rho\left(L_{F}, L_{A}\right)=0.51
$$

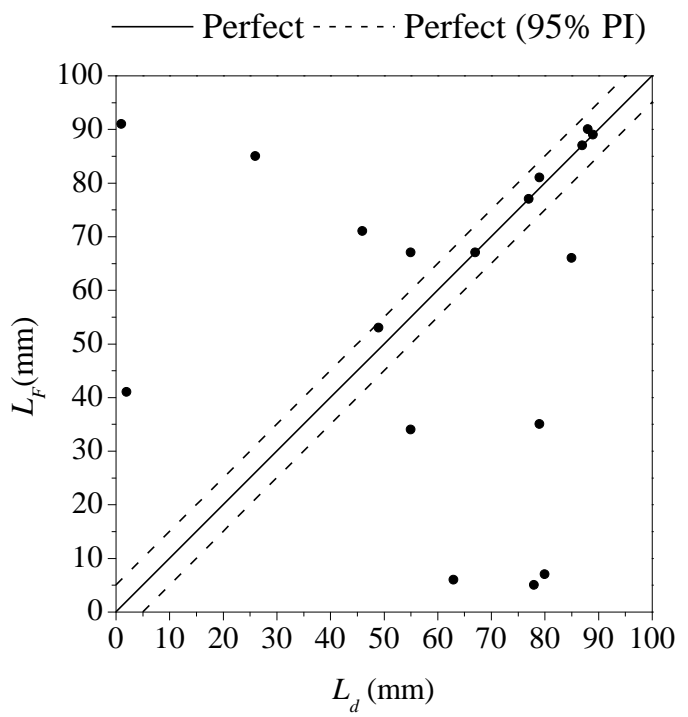

Fig.21b $L_{F}$ vs $L_{d}$ (18 specimens)

$$
\rho\left(L_{F}, L_{d}\right)=-0.06
$$




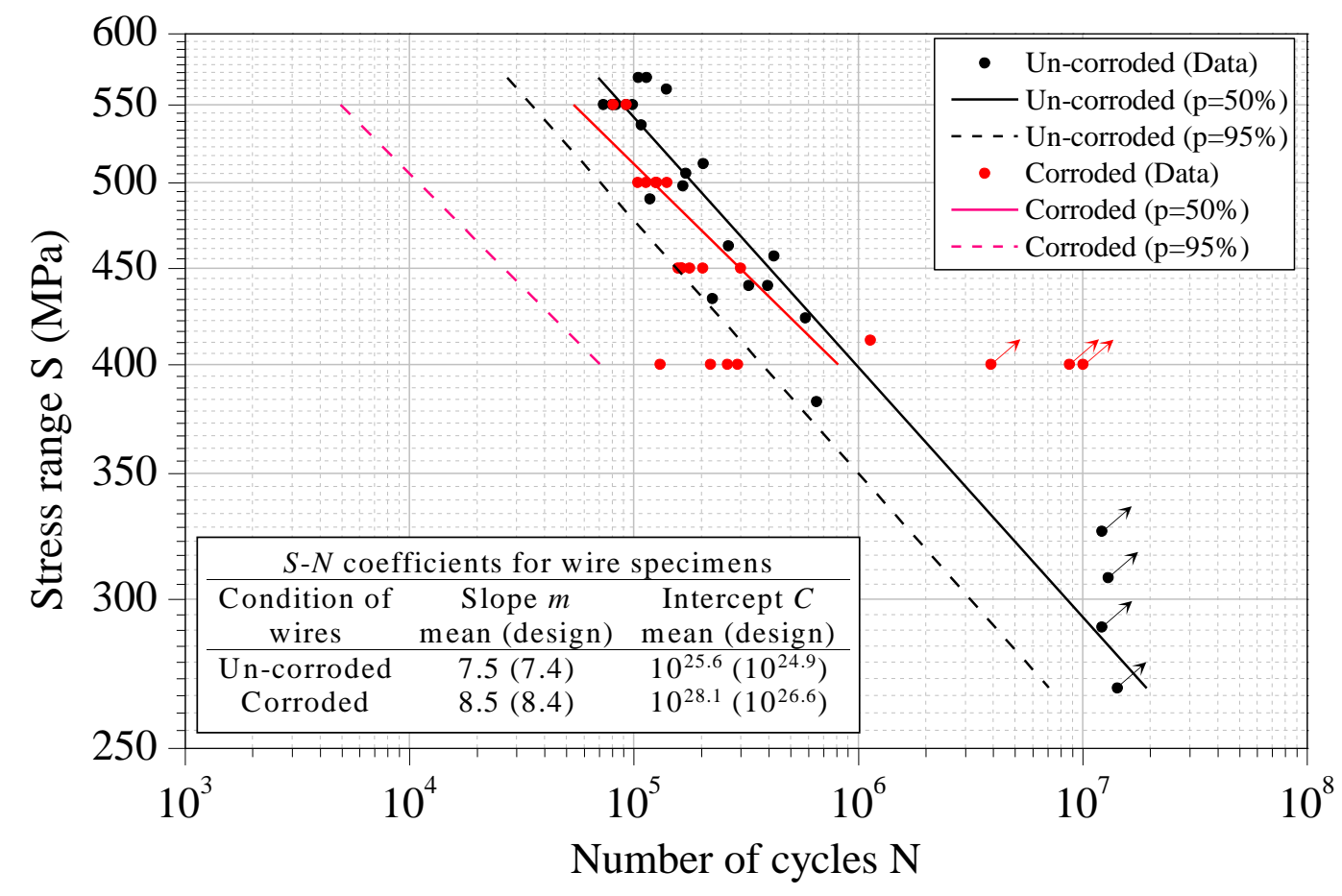

Fig.22a S-N Curves of un-corroded and corroded wire

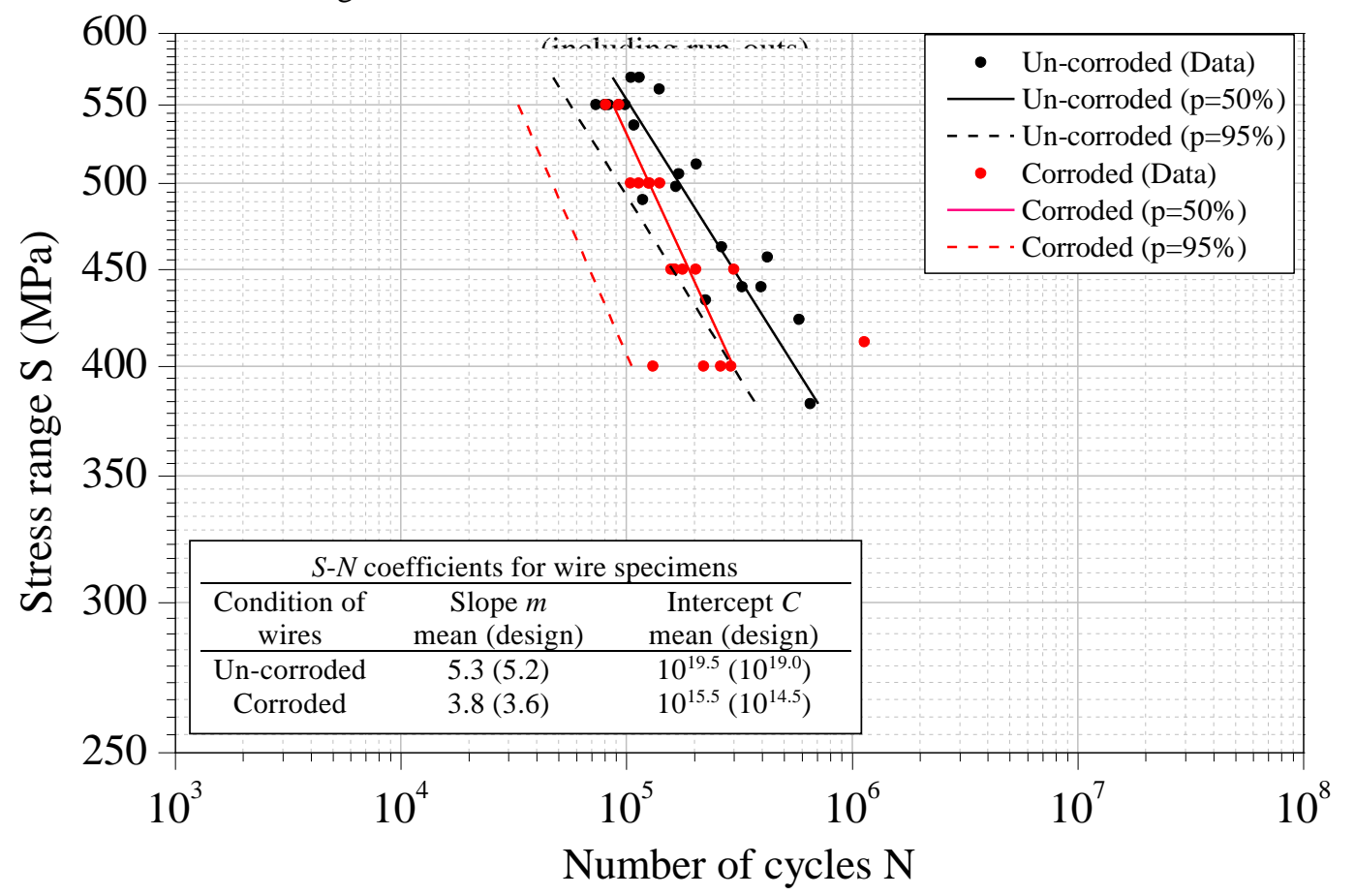

Fig.22b S-N Curves of un-corroded and corroded wire 